\title{
Hydroxylamine Derivatives as a New Paradigm in the Search of Antibacterial Agents
}

\author{
Laia Miret-Casals, ${ }^{\dagger, \#}$ Aida Baelo, ${ }^{\ddagger}, \#$ Esther Julián, ${ }^{\S}$ Josep Astola, ${ }^{\ddagger}$ Ariadna Lobo-Ruiz, ${ }^{\dagger}$ \\ Fernando Albericio, $*,+, \|, \perp_{(0)}$ and Eduard Torrents $*, \neq(0)$
}

${ }^{\dagger}$ Department of Organic Chemistry, University of Barcelona, C/ Martí i Franquès, 1-11, 08028 Barcelona, Spain

${ }^{\ddagger}$ Bacterial Infections: Antimicrobial Therapies, Institute for Bioengineering of Catalonia (IBEC), The Barcelona Institute of Science and Technology, Baldiri Reixac, 15-21, 08028 Barcelona, Spain

${ }^{\S}$ Group of Mycobacteriology, Department of Genetics and Microbiology, Facultat de Biociències Universitat Autònoma de Barcelona, Building C, 08193 Bellaterra, Barcelona, Spain

"CIBER-BBN, Networking Centre on Bioengineering, Biomaterials and Nanomedicine, C/ Martí i Franquès, 1-11, 08028 Barcelona, Spain

${ }^{\perp}$ School of Chemistry \& Physics, University of Kwazulu-Natal, Private Bag X01, Scottsville, Pietermaritzburg 3209, South Africa

\section{Supporting Information}

ABSTRACT: Serious infections caused by bacteria that are resistant to commonly used antibiotics have become a major global healthcare problem in the 21 st century. Multidrug-resistant bacteria causing severe infections mainly grow in complex bacterial communities known as biofilms, in which bacterial resistance to antibacterial agents and to the host immune system is strengthened. As drug resistance is becoming a threatening problem, it is necessary to develop new antimicrobial agents with novel mechanisms of action. Here, we designed and synthesized a small library of $N$-substituted hydroxylamine (N-HA) compounds with antibacterial activity. These compounds, acting as radical scavengers, inhibit the bacterial ribonucleotide reductase (RNR) enzyme. RNR enzyme is essential for bacterial proliferation during infection, as it provides the building blocks for DNA synthesis and repair. We demonstrate the broad antimicrobial effect of several drug candidates against a variety of Gram-positive and Gram-negative bacteria, together with low toxicity toward eukaryotic cells. Furthermore, the most promising compounds can reduce the biomass of an established biofilm on Pseudomonas aeruginosa, Staphylococcus aureus, and Escherichia coli. This study settles the starting point to develop new $\mathrm{N}$-hydroxylamine compounds as potential effective antibacterial agents to fight against drug-resistant pathogenic bacteria.

\section{INTRODUCTION}

Ever since antibiotics were introduced worldwide, bacterial pathogens have been developing resistance, which reduces drastically or eliminates their effectiveness. The emergence of drug-resistant bacteria is a growing challenge to anti-infective therapy. Worldwide bacteria species that have acquired multiple drug resistance and escaped the effects from our current antimicrobial drugs include different important bacterial pathogens. ${ }^{1}$ Several bacterial pathogens such as methicillin- and vancomycin-resistant Staphylococcus aureus (MRSA and VRSA) or multidrug resistant Pseudomonas aeruginosa are resistant to almost all clinically available antibacterial drugs. ${ }^{2}$ Moreover, recent estimates suggest that bacterial biofilms account for over $80 \%$ of microbial infections in the human body. ${ }^{3,4}$ Bacterial biofilms are dense aggregates of cell-cell surface-attached microorganisms encased in a selfsynthesized hydrated extracellular polymeric substances matrix. ${ }^{5}$ Bacterial pathogens living in biofilms are hard to eradicate because of different strategies that involve restricted penetration of antimicrobials, resistance to the immune system, differential physiological activity with slow metabolism, the presence of phenotypic variants and persisters, efflux systems, and enhanced repair systems. ${ }^{6,7}$

The lack of new antibiotics in the drug development pipeline, especially those with new modes of action and active against bacteria, worsens the situation. In this context, the search of new antimicrobials acting on new targets is a critical challenge. Searching for new compounds or strategies to decrease bacterial biofilm formation and avoid antibiotic resistance is a critical stage essential for the treatment of biofilm-associated diseases. ${ }^{8}$

Received: June 19, 2018

Accepted: November 28, 2018

Published: December 11, 2018 


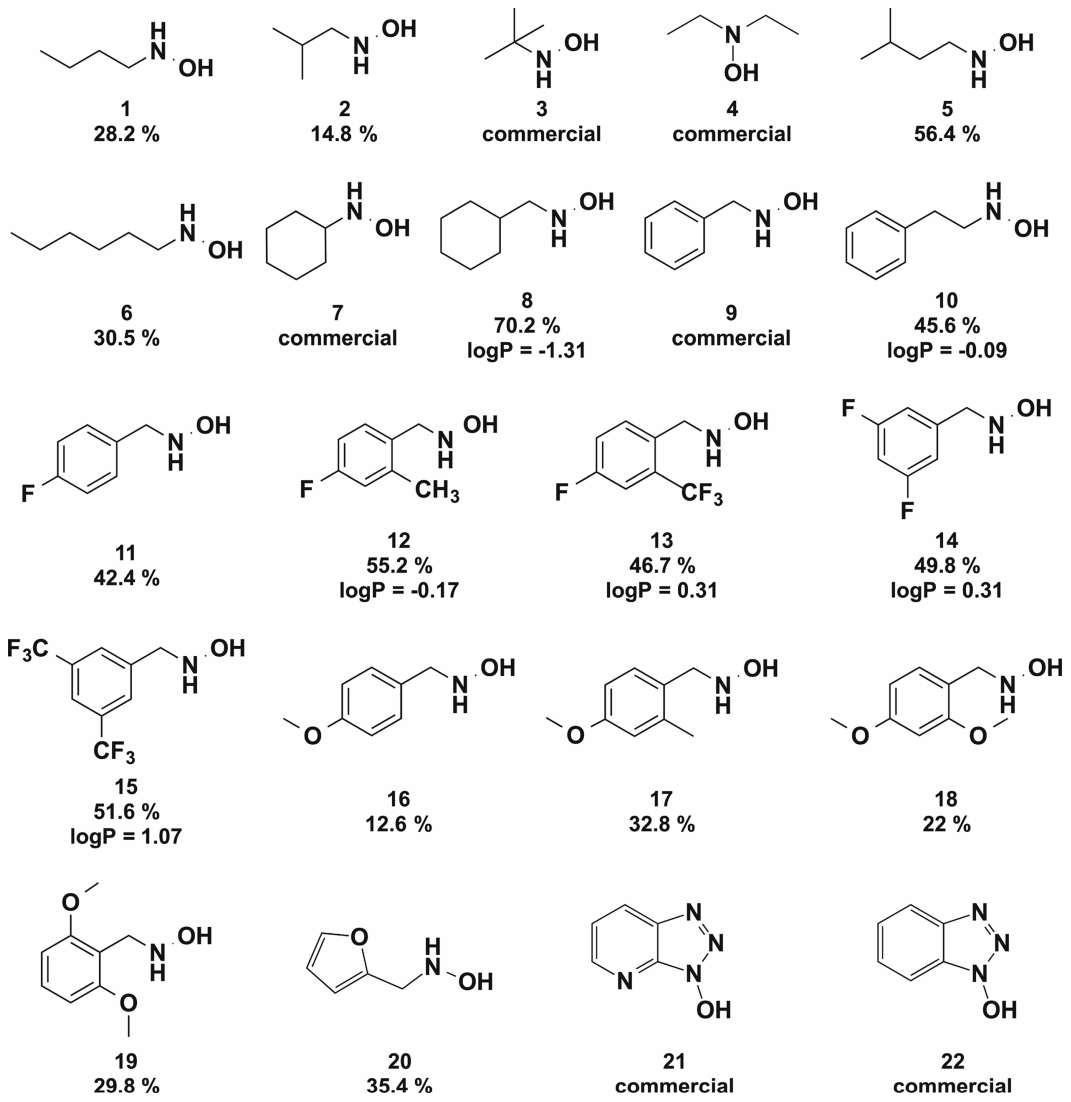

Figure 1. Library of N-HAs. Chemical structures of the N-HA compounds, designed to target the bacterial RNR enzyme, are shown. The synthesis yield obtained for each compound is shown in \%, with the exception of the compounds acquired commercially. Log $P$ values of representative candidates are indicated.

Ribonucleotide reductase (RNR) enzyme has shown to be an antimicrobial drug target for the treatment of several infections. ${ }^{9}$ RNR exclusively supplies the nucleotide precursors for DNA synthesis and repair by catalyzing the reduction of ribonucleotides (NTPs) to their corresponding deoxyribonucleotides (dNTPs) via radical chemistry. Modulation of RNR activity is a rate-limiting step in DNA synthesis. Therefore, inactivation of RNR activity ceases DNA synthesis and, consequently, inhibits cell proliferation. Thus, RNR is essential for all bacteria causing both acute and biofilm infection, as they need to multiply and replicate its genome within the host and, therefore, need a constant supply of the four different dNTPs for the synthesis of the new DNA.

Up to date, three different main RNR classes are described (class I, II, and III), differing in their cofactor requirements and quaternary structures. ${ }^{9-12}$ Class I RNR is additionally subdivided into class Ia, class Ib, and class Ic, depending on the metal type of the metallocofactor of the enzyme. Class I RNRs are tetrameric $\left(\alpha_{2} \beta_{2}\right)$ enzymes, composed of two homodimeric proteins: R1 $\left(\alpha_{2}\right)$, which contains the catalytic domain (active site) and the complex allosteric domain (responsible for the regulation of the enzyme), and R2 $\left(\beta_{2}\right)$, which carries a stable tyrosyl radical and an oxygen-linked diiron center required for free-radical production. Once the radical has been generated, an electron transfer takes place between $\beta_{2}$ and $\alpha_{2}$ subunits to catalyze the reduction of NTPs to their corresponding dNTPs.

Although both bacteria and eukaryotic cells codify for RNR, there are remarkable differences between them, as the sequence similarity between them is quite low, ${ }^{13}$ and hence, specific inhibitors can potentially be designed to differentially target bacterial RNRs. In addition, eukaryotic cells only encode for one RNR class (class Ia), whereas bacterial species can encode simultaneously for different RNR classes, thus making bacterial RNR system an attractive target for antibacterial therapies.

Numerous and diverse RNR inhibitors have been described during the last decades, including different inhibitor families such as free-radical scavengers, iron chelators, and substrate analogues, among others. ${ }^{18-18}$ Radical scavenger compounds are well known to inhibit RNR by quenching an essential tyrosyl free radical, located in the small class I subunit, ${ }^{19,20}$ which is required to generate the reduction power in the catalytic subunit of the enzyme. Several radical scavenger molecules, such as hydroxyurea (HU), didox, trimidox, and hydroxyguanidine, have been shown to be useful for the treatment of different cancer diseases. ${ }^{16}$ One of these compounds, hydroxyurea, was used for general cancer treatment and is commonly used nowadays for the treatment of some specific ones. ${ }^{21,22}$ Although these compounds inhibit bacterial replication inhibiting bacterial RNR, they cannot be used to treat bacterial infections because of the high toxicity toward eukaryotic cells. Recently, we have identified "NH$\mathrm{OH}^{\prime}$ moiety as an important radical scavenger family by itself. $\mathrm{N}$-Methylhydroxylamine (M-HA) is a compound with a high capacity to specifically inhibit the Bacillus anthracis RNR without interfering the activity of eukaryotic RNR, thus being nontoxic. ${ }^{19,20}$ We have also proven the antibacterial capacity of this radical scavenger on Pseudomonas and Mycobacterium infections. $^{23}$ This discovery opens new horizons in the 
development, identification, and investigation of the use of $\mathrm{N}$ substituted hydroxylamine (N-HA) compounds as specific antimicrobial RNR inhibitors.

\section{RESULTS}

Design and Synthesis of the N-HA Library. We previously described the antibacterial activity of M-HA, a radical scavenger compound that specifically targets bacterial RNR without interfering the host enzyme. ${ }^{19,23}$ It is known that low-molecular-weight compounds, such as M-HA, might have effects on structurally unrelated proteins. For this reason, we designed and synthesized a small library of N-HA compounds with different structures to better cover the chemical space and gain more selectivity (Figure 1) to directly target the bacterial class I RNR enzyme (class Ia and class Ib), acting as an antibacterial agent.

The N-HA library was generated to identify novel drugs with high free-radical scavenging (FRS) activity against RNR enzymes. As the FRS activity is based on the ability of the molecule to donate a hydrogen ion to a free radical, FRS activity of N-HAs will depend on the homolytic bond dissociation enthalpies (BDEs) of the $\mathrm{O}-\mathrm{H}$ bond of hydroxylamines. It has been predicted by computational methods that the resonance and the inductive effects are important in the BDEs of the $\mathrm{O}-\mathrm{H}$ bond of $\mathrm{N}$-monosubstituted hydroxylamines. Thus, the design of N-HA with electron-donating inductive effects and resonance effects makes the corresponding $N$-oxyl species more electron-rich and more stable radicals, leading to a BDE decrease ${ }^{24,25}$ and thus resulting in a higher FRS activity. Otherwise, the presence of electron-withdrawing groups or no resonance effects will generate an opposite effect, destabilizing the produced radicals, increasing BDE, and consequently, decreasing FRS activity.

The synthesis of N-HA products was accomplished by reductive amination of aldehydes, as described before ${ }^{26}$ with some variations, by a general one-pot synthesis that involves the conversion of a carbonyl group to the hydroxylamine via the corresponding $N$-hydroxyimine (Scheme 1).

Scheme 1. General Synthetic Scheme for the Synthesis of the $\mathrm{N}$-Hydroxylamine Compounds

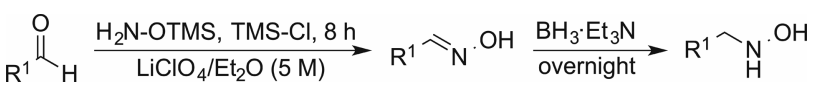

Initially, $N$-alkyl hydroxylamine isomers of four carbon atoms, including a secondary hydroxylamine and additional analogues, increasing the alkyl chain length to increase the electron-donating inductive effect to stabilize the generated radical, were synthesized or purchased (1-6). Moreover, $\mathrm{N}$ cycloalkyl hydroxylamine derivatives were incorporated to the library (7 and 8) to elucidate the importance of linear and cyclic aliphatic structures in the stabilization of hydroxylamine's radicals. Replacement of the aliphatic moiety in $\mathrm{N}$ hydroxylamine compounds by an aromatic ring, such as benzyl or homobenzyl group, was also explored to increase FRS activity due to delocalization of the free radical throughout the aromatic ring structure (9 and 10). To further study if radical stabilization by resonance effects can be affected by inductive effects, $N$-hydroxylamine compounds with electron-withdrawing substituents in the aromatic ring, such as fluorine and trifluoromethyl (11-15), were synthesized. In addition, the library was further extended with a series of $N$-hydroxylamine compounds with electron-donating substituents in the aromatic ring, such as methyl and methoxy (16-19). Finally, $\mathrm{N}$-hydroxylamines containing a heteroaryl group or being part of the heterocycle as secondary hydroxylamines were also synthesized or purchased, respectively (20-22), to study the ability of heteroaromatics in stabilizing $N$-oxyl species.

Identification of New $\mathrm{N}$-Hydroxylamines (N-HAs) with Antimicrobial Activity against Both Gram-Positive and Gram-Negative Bacteria. In the antibacterial activity screening of the newly synthesized N-HAs, compounds were tested against four Gram-positive (B. anthracis, Staph. aureus, Staphylococcus epidermidis, and Enterococcus faecalis) and two Gram-negative ( $P$. aeruginosa and Escherichia coli) clinically relevant bacterial strains, and their minimum inhibitory concentrations (MICs) were determined (Table 1). As a reference, an importantly used antibiotic, ciprofloxacin (CIP), was also tested. As shown in Table 1, we also included the M$\mathrm{HA}$ and $\mathrm{HU}$ antibacterial and cytotoxicity values to compare them with the new data.

Some of the compounds $(1-5,7,9,13,16$, and 19-22) showed no antibacterial activity in any bacteria tested $\left(\mathrm{MIC}_{50}\right.$ $>1000 \mu \mathrm{g} / \mathrm{mL}$ ) (data not shown). In general, Gram-positive bacteria species (encoding class Ib RNR) were more sensitive to $6,8,10,11,15,17$, and 18 . In particular, compounds 11 and 17 with an $\mathrm{MIC}_{50}$ value of $<15 \mu \mathrm{g} / \mathrm{mL}$ showed higher activity compared to M-HA against $B$. anthracis. Compounds 11 and 15 showed also high antimicrobial activity against both Staph. aureus and Staph. epidermidis with an $\mathrm{MIC}_{50}$ value of $<60 \mu \mathrm{g} / \mathrm{mL}$ compared to M-HA and HU. Compound 18 also showed antibacterial activity against Staph. epidermidis with an $\mathrm{MIC}_{50}$ value of $<40 \mu \mathrm{g} / \mathrm{mL}$. Compounds 14 and 17 showed antimicrobial activity against $E$. faecalis with an $\mathrm{MIC}_{50}$ value of $<80 \mu \mathrm{g} / \mathrm{mL}$.

Gram-negative bacterial species exhibited high resistance to most of the compounds. Compound $\mathbf{8}$, showing values similar to M-HA, was the most active, highly inhibiting the growth of $P$. aeruginosa with an $\mathrm{MIC}_{50}$ value lower than $17 \mu \mathrm{g} / \mathrm{mL}$ and that of $E$. coli with an $\mathrm{MIC}_{50}$ value lower than $60 \mu \mathrm{g} / \mathrm{mL}$. Compound 12 also resulted in high antimicrobial activity against $P$. aeruginosa $\left(\mathrm{MIC}_{50}<70 \mu \mathrm{g} / \mathrm{mL}\right)$, and compound 15 was also effective against E. coli $\left(\mathrm{MIC}_{50}<60 \mu \mathrm{g} / \mathrm{mL}\right)$.

None of the $N$-hydroxylamine derivatives containing linear alkyl groups with less than six carbon atoms were active against any bacterial species tested, despite the fact that $\mathrm{M}-\mathrm{HA}$ is active with one carbon atom.

These results indicate that inductive effects generated by linear alkyl groups with less than six carbon atoms are insufficient to stabilize $\mathrm{N}$-oxyl species, except for the case of $\mathrm{M}$ HA. Compound 6, a linear aliphatic $N$-hydroxylamine with six carbon atoms, and compound $\mathbf{8}$, a cyclic aliphatic hydroxylamine with seven atom carbons, exhibited antimicrobial activity against Gram-positive and Gram-negative bacteria, respectively. $\mathrm{N}$-Homobenzylhydroxylamine $(\mathbf{1 0})$ and some $\mathrm{N}$ benzylhydroxylamine analogues with substituents in the aromatic ring $(11,12,14,15,17$, and 18) exhibited higher antimicrobial activity compared to the aliphatic $N$-hydroxylamines. These results might indicate that conjugate rings lead to stable spin delocalized systems, providing stabilizing effects for $N$-oxyl species radicals generated by reduction of the tyrosyl radical of the RNR enzyme. This fact highlights the importance of the resonance effects compared to the inductive effects in the stabilization of radicals. Furthermore, the effect of the delocalization of the free radical throughout the aromatic 
Table 1. Antibacterial and Cytotoxic Activities of the N-HA Compounds

\begin{tabular}{|c|c|c|c|c|c|c|c|}
\hline \multirow[b]{3}{*}{ compound } & \multicolumn{6}{|c|}{$\operatorname{MIC}_{50}(\mu \mathrm{g} / \mathrm{mL})^{a}$} & \multirow[b]{3}{*}{$\mathrm{CC}_{50}(\mu \mathrm{g} / \mathrm{mL})$} \\
\hline & \multicolumn{4}{|c|}{ Gram-positive $^{b}$} & \multicolumn{2}{|c|}{ Gram-negative $^{c}$} & \\
\hline & Bant & Saur & Sepi & Efae & Paer & $E c o l$ & \\
\hline 6 & $55(8.5)$ & $(-)$ & $(-)$ & $(-)$ & $(-)$ & $(-)$ & $468 \pm 7.64$ \\
\hline 8 & $60(3)$ & $60(3)$ & $60(3)$ & $120(1.5)$ & $17(\mathbf{1 0 . 5})$ & $60(3)$ & $178 \pm 12.4$ \\
\hline 10 & $65(4)$ & $65(4)$ & $65(4)$ & $(-)$ & $125(2)$ & $125(2)$ & $259 \pm 9.50$ \\
\hline 11 & $15(21.3)$ & $60(5.3)$ & $30(10.6)$ & $125(2.6)$ & $(-)$ & $(-)$ & $320 \pm 5.03$ \\
\hline 12 & $(-)$ & $(-)$ & $70(1.9)$ & $(-)$ & $70(1.9)$ & $(-)$ & $131 \pm 21.9$ \\
\hline 14 & $(-)$ & $150(1.2)$ & $(-)$ & $70(2.4)$ & $150(1.2)$ & $(-)$ & $168 \pm 13.5$ \\
\hline 15 & $32(21.2)$ & $60(11.4)$ & $60(11.4)$ & $(-)$ & $(-)$ & $60(11.4)$ & $686 \pm 45.4$ \\
\hline 17 & $8(45.2)$ & $(-)$ & $80(4.5)$ & $80(4.5)$ & $(-)$ & $(-)$ & $362 \pm 20.4$ \\
\hline 18 & $40(45)$ & $175(2.4)$ & $40(10.4)$ & $175(2.4)$ & $(-)$ & $(-)$ & $415 \pm 29.5$ \\
\hline $\mathrm{HU}$ & $(-)$ & $280(0.1)$ & $295(0.1)$ & $90(0.33)$ & $15(2)$ & $240(0.1)$ & $30 \pm 3.4$ \\
\hline M-HA & $22(14.5)$ & $70(4.6)$ & $75(4.2)$ & $45(7.1)$ & $20(16)$ & $40(8)$ & $320 \pm 20.4$ \\
\hline CIP & $0.5(2600)$ & $0.5(2600)$ & $0.5(2600)$ & $0.5(2600)$ & $0.25(5100)$ & $0.25(5100)$ & $1324 \pm 49.3$ \\
\hline
\end{tabular}

${ }^{a}$ The $\mathrm{MIC}_{50}$ values $(\mu \mathrm{g} / \mathrm{mL})$ measured after $8 \mathrm{~h}$ of N-HA compounds compared to HU, M-HA, and CIP (used as the positive control) are shown. Data is representative of three independent experiments. ${ }^{b}$ B. anthracis Sterne $7700 \mathrm{pXO1}-1 \mathrm{pXO} 2^{-}$(Bant), Staph. aureus ATCC 12600 (Saur), Staph. epidermidis ATCC 1798 (Sepi), and E. faecalis ATCC 19433 (Efae). ${ }^{c}$ P. aeruginosa ATCC 15692 (Paer) and E. coli O157:H7 (Ecol). (-), no antibacterial activity $\left(\mathrm{MIC}_{50}>250\right)$. Cytotoxicity values in murine macrophages measured after $24 \mathrm{~h}$ are indicated $\left(\mathrm{CC}_{50}\right)$ as well as their $\mathrm{SI}($ in parenthesis next to the $\mathrm{MIC}_{50}$ value). Selectivity indexes of $\geq 5$ are in bold. Compounds with $\mathrm{MIC}_{50}$ values over $1000 \mu \mathrm{g} / \mathrm{mL}$ in all the strains are not shown $(1,2,3,4,5,7,9,13,16,19,20,21$, and 22).

ring structure overlaps the inductive effect generated by substituents in the aromatic ring. $\mathrm{N}$-Hydroxylamine derivatives with electron-withdrawing substituents and/or electron-donating substituents in the aromatic ring were active against several bacterial species with no distinction. $\mathrm{N}$-Hydroxylamines containing a heteroaryl group or being part of the heterocycle as secondary hydroxylamines showed no antibacterial activity in any bacteria tested. However, $N$-benzylhydroxylamine analogues $(9,13,16$, and 19) showed no antibacterial activity and clearly demonstrate a challenge to capture a structureactivity relationship. We believe that radical scavenger molecules could interact in different places along the protein electron chain transfer pathway from the $\beta_{2}$ to the $\alpha_{2}$ subunits, and this explains why radical scavengers without a common scaffold are active.

Selected N-HA Compounds Exhibit Low Cytotoxicity and Good Lipophilicity Indexes. To validate hydroxylamine compounds to be used as drug candidates, eukaryotic cytotoxicity of the compounds showing higher activity against bacterial species $(6,8,10-12,14,15,17$, and 18) was determined in murine macrophages (see Experimental Section) as described in our previous work. ${ }^{23}$ Compounds with no antibacterial activity in the initial screening were discarded.

The $50 \%$ cytotoxic inhibitory concentration $\left(\mathrm{CC}_{50}\right)$ values were determined from dose-response data obtained from the toxicity assay of macrophages. Therapeutic indexes (selectivity index, SI), defined as $\mathrm{SI}=\mathrm{CC}_{50} / \mathrm{MIC}_{50}$, were calculated (see Table 1) to measure drug safety $(\mathrm{SI}>10)$. Compounds with high $\mathrm{CC}_{50}$ and low $\mathrm{MIC}_{50}$ have higher therapeutic index and are safer compared to compounds with low SI values.

Compounds 11, 15, 17, and 18 showed higher SI in Grampositive bacteria: in the case of $B$. anthracis, SI values of 21.3, 21.2, 45.2, and 45, respectively, and in Staph. aureus, SI values of 5.3 and 11.4 for compounds 11 and 15, respectively. Compounds 11, 15, and 18 showed SI values of 10.6, 11.4, and 10.4 in Staph. epidermidis, respectively. For Gram-negative bacteria, the best SI values were achieved with compound 8 in the case of $P$. aeruginosa $(\mathrm{SI}=10.5)$ and compound $\mathbf{1 5}$ in the case of E. coli $(\mathrm{SI}=11.4)$. Although compound 12 was active against $P$. aeruginosa, $\mathrm{SI}$ index was lower due to a lower $\mathrm{CC}_{50}$ value. Still, further studies were carried with this compound to have more active N-HA compounds analyzed in the case of Gram-negative bacteria. Clearly, some of the compounds improve the SI values of the HU and M-HA compounds previously analyzed, especially against Gram-positive bacteria.

To further test $N$-hydroxylamine compounds as drug candidates, the lipophilicity of representative N-HA candidates (8, 10, and 12-15) was measured by calculating the $n$ octanol-water partition coefficients in their logarithmic form $(\log P)$ (Figure 1). The majority of the $N$-hydroxylamine analogues exhibited a moderate lipophilicity $(\log P$ between 0 and 3), indicating a good balance between solubility and permeability, which is optimal for oral absorption and cell membrane permeation through passive transport.

N-HA Compounds Inhibit Bacterial Growth through their Radical Scavenging Activity in Bacterial RNR. To confirm that novel $\mathrm{N}$-hydroxylamines inhibit bacterial growth by inhibiting radical formation in bacterial RNR, the FRS activities of compounds showing antibacterial activity $(6,8$, $10-12,14,15,17$, and 18) were evaluated through a radical scavenging assay by trapping the $\mathrm{DPPH}$ - radical as previously described $^{27}$ (see Experimental Section). Ascorbic acid (AA), $\mathrm{HU}$, and M-HA were used as positive radical scavenger controls (Table 2). After $8 \mathrm{~h}$ of incubation and using a DPPH. concentration of $70 \mu \mathrm{M}$, compounds $8,10,11,12,14,15,17$, and 18 were able to scavenge the $\mathrm{DPPH}$. radical with $\mathrm{IC}_{50}$ values of $9.3,14.3,6.4,4.2,23.1,8.1,4.8$, and $6.5 \mu \mathrm{M}$, respectively, showing similar scavenging activity as $\mathrm{AA}\left(\mathrm{IC}_{50}\right.$ $=10.2 \mu \mathrm{M})$, $\mathrm{HU}\left(\mathrm{IC}_{50}=8.6 \mu \mathrm{M}\right)$, and $\mathrm{M}-\mathrm{HA}\left(\mathrm{IC}_{50}=20.3\right.$ $\mu \mathrm{M})$. Similar values were obtained at $12 \mathrm{~h}$ incubation time. However, compounds 2, 3, and 6, with linear aliphatic N-HA with antibacterial activity, displayed a low FRS activity compared to cyclic aliphatic hydroxylamine (8), N-homobenzylhydroxylamine (10), and $N$-benzylhydroxylamine analogues $\left(11,12,14,15,17\right.$, and 18) with $\mathrm{IC}_{50}$ values higher than $140 \mu \mathrm{M}$. This study indicates that cyclic aliphatic rings and aromatic rings make corresponding $\mathrm{N}$-oxyl species more 
Table 2. Radical Scavenging Capacity of the N-HAs

\begin{tabular}{lcc} 
& \multicolumn{2}{c}{ DPPH. scavenging activity $\left(\mathrm{IC}_{50}(\mu \mathrm{M})\right)^{a}$} \\
\cline { 2 - 3 } compounds & $8 \mathrm{~h}$ incubation time & $12 \mathrm{~h}$ incubation time \\
$\mathbf{2}$ & $>256$ & $>256$ \\
$\mathbf{3}$ & $>256$ & $>256$ \\
$\mathbf{6}$ & $171.4 \pm 23.0$ & $141.3 \pm 17.4$ \\
$\mathbf{8}$ & $9.3 \pm 0.7$ & $8.6 \pm 0.5$ \\
$\mathbf{1 0}$ & $14.3 \pm 0.8$ & $13.7 \pm 0.9$ \\
$\mathbf{1 1}$ & $6.4 \pm 0.4$ & $5.8 \pm 0.3$ \\
$\mathbf{1 2}$ & $4.2 \pm 0.3$ & $3.8 \pm 0.3$ \\
$\mathbf{1 4}$ & $23.1 \pm 0.2$ & $20.5 \pm 0.3$ \\
$\mathbf{1 5}$ & $8.1 \pm 0.5$ & $7.6 \pm 0.5$ \\
$\mathbf{1 7}$ & $4.8 \pm 0.6$ & $4.4 \pm 0.8$ \\
$\mathbf{1 8}$ & $6.5 \pm 0.6$ & $5.8 \pm 0.6$ \\
AA & $10.2 \pm 1.8$ & $10.1 \pm 1.8$ \\
HU & $8.6 \pm 1.2$ & $7.5 \pm 0.9$ \\
M-HA & $20.3 \pm 2.0$ & $18.1 \pm 1.5$
\end{tabular}

${ }^{a}$ Radical scavenging capacity was evaluated by measuring the reduction of the free radical DPPH. spectrophotometrically after incubating each compound with the DPPH during 8 and $12 \mathrm{~h}$. AA, $\mathrm{HU}$, and M-HA were used as positive controls.

electron-rich and more stable radicals, leading to a BDE decrease and thus resulting in a higher FRS activity, as we previously discussed. Also, our data supports the view that these compounds exhibit a similar capacity to scavenge RNR generated radical as other well-known RNR radical inhibitors such as HU and M-HA do (see Table 2).

To evaluate the specific inhibitory effect of the N-HA compounds in bacterial RNR, $P$. aeruginosa purine deoxyribonucleotide levels were quantified at exponential phase in the presence of N-HA compounds (8 and 12) and HU (positive control) at $5 \mathrm{mM}$ for $3 \mathrm{~h}$ and in the absence of or any added compound (negative control) (Figure 2A). Relative dNTP levels were quantified in the different extracts carrying out the diphenylamine (DPA) assay. ${ }^{28,29}$ The results showed a significant decrease of dNTP levels when $P$. aeruginosa was treated with compounds 8 and 12 (7.45\% and $67.50 \%$ reduction, respectively) compared to negative control. HU, used as the positive control, also showed a reduction of $65.45 \%$ in dNTP levels.

The role of the radical scavenger $\mathrm{HU}$ in the inhibition of RNR has been well studied. As many other enzymatic inhibitors, when using $\mathrm{HU}$, there is an induction of the expression of the inhibited enzyme (RNR), as it has been previously well described for us and many other authors. ${ }^{29,30}$

The induction of the expression of $P$. aeruginosa PAO1 class Ia RNR ( NrdA) was studied in the presence of the most active N-HA radical scavengers against $P$. aeruginosa, using $\mathrm{HU}$ as a positive control. A Western blot was performed using protein extracts from PAO1 cultures in which $\mathrm{HU}, \mathbf{8}$, or $\mathbf{1 2}$ was added (at initial exponential phase and left for $3 \mathrm{~h}$ ). As shown, both 8 and 12 were able to induce NrdA expression (1.6 and 3 times more, respectively) compared to the negative control, which was left without adding any compound. Compounds $\mathbf{8}$ and $\mathbf{1 2}$ had similar effects on NrdA expression to the ones HU shows (nine times of induction), showing the direct effect of the newly synthesized N-HA compounds on bacterial RNR expression (Figure 2B).

N-HA Compounds Display Antibacterial Activity through a Bacteriostatic Mode of Action. To better understand how the most active $N$-hydroxylamines affect the

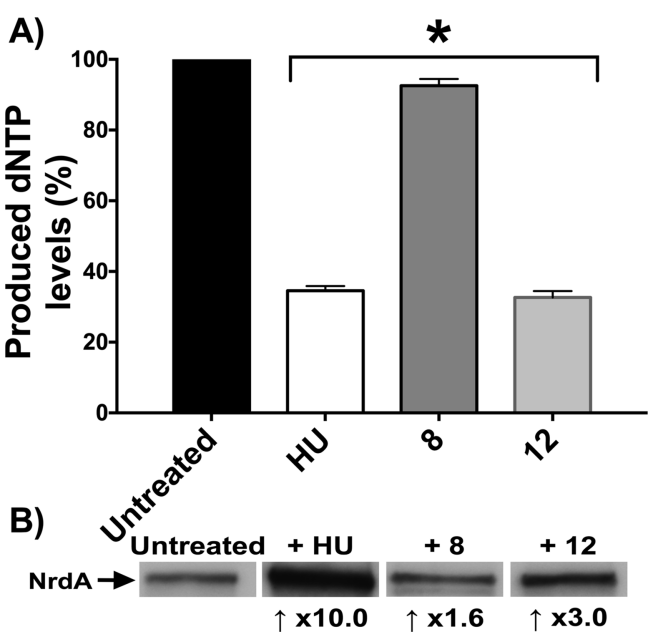

Figure 2. Inhibition of bacterial RNR by N-HA compounds. (A) In vivo inhibition of bacterial RNR in $P$. aeruginosa was determined by using DPA assay to estimate dNTP levels. Relative dNTP levels were measured in protein extracts from mid-exponential cultures incubated with or without $5 \mathrm{mM}$ of the radical scavengers 8,12 , or $\mathrm{HU}$ (positive control) for $3 \mathrm{~h}$. Percentage of produced dNTPs is shown for each sample using untreated culture as a reference. The results shown represent the mean $\pm S D$ of two replicates of one representative experiment. An unpaired $t$ test, compared to the untreated sample, was performed to evaluate significant differences $(*, P<0.05)$. (B). Western blot analysis of class Ia RNR (NrdA) of bacteria at midexponential phase cultured in the presence of $5 \mathrm{mM}$ of $\mathbf{8 , 1 2}$, or $\mathrm{HU}$ for $3 \mathrm{~h}$. The Western blot is representative of two independent experiments.

viability of bacterial cells in terms of physiological changes, bacterial cells were imaged through fluorescence microscopy using the Live/Dead viability assay (see Experimental Section), which allows measuring bacterial viability in terms of membrane integrity. SYTO 9 green fluorescent nucleic acid dye is able to penetrate all membrane cells, labeling all bacteria, whereas propidium iodide can only enter bacteria cells with damaged membrane.

Staph. aureus, $P$. aeruginosa, E. coli, and B. anthracis growing cultures at early exponential phase were incubated with selected N-HA compounds showing greater antibacterial action for $2 \mathrm{~h}$ then subsequently stained and imaged using fluorescence microscopy (Figure 3). Images of bacteria also treated with antibiotics novobiocin (NVB) and CIP were taken to compare the effects with known antibiotics. N-HA compounds did not affect membrane integrity of the cells, as no differences were observed in the ratio of green cells (viable) and red cells (nonviable) with or without any of the treatments demonstrating a bacteriostatic property of these compounds. The same effect was previously described for other radical scavengers such as HU, hydroxylamine, and M-HA. ${ }^{23}$

N-HA Compounds Show Antibiofilm Activity against Different Pathogens. Because most of the bacterial infections in humans are in biofilm form, ${ }^{3,31}$ it is crucial to study the antibacterial activity under the growth condition in which bacteria are found naturally more resistant to the action of antimicrobials. ${ }^{7,31}$ The most promising compounds showing higher antibacterial activity, together with low cytotoxicity (highest SI values), were evaluated on P. aeruginosa, Staph. aureus, and E. coli static biofilms.

P. aeruginosa, Staph. aureus, and E. coli bacterial biofilms (72 $\mathrm{h}$ old) were established and treated with repeated admin- 

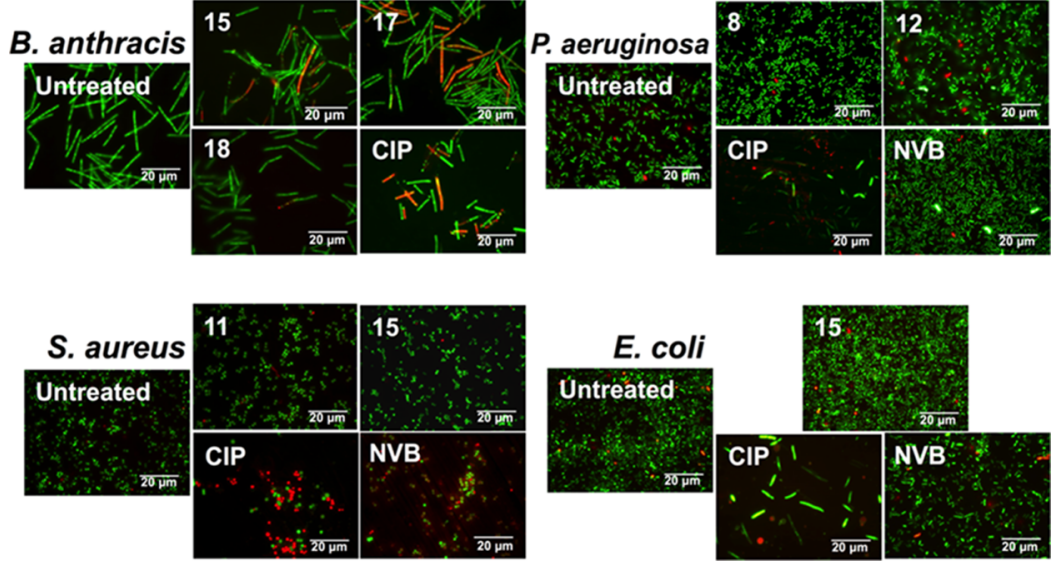

Figure 3. Bacterial viability after different compound treatments. Bacterial cultures were visualized under fluorescence microscopy after $2 \mathrm{~h}$ exposition with the different N-HAs at $1 \times$ MIC concentration. Images were taken at $100 \times$. Scale bars shown represent a real distance of $20 \mu \mathrm{m}$. Live cells were green (SYTO 9 dye), and dead cells were red (propidium iodide dye). CIP and NVB ( $50 \mu \mathrm{g} / \mathrm{mL}$ ) were used.

\section{A) $P$. aeruginosa}
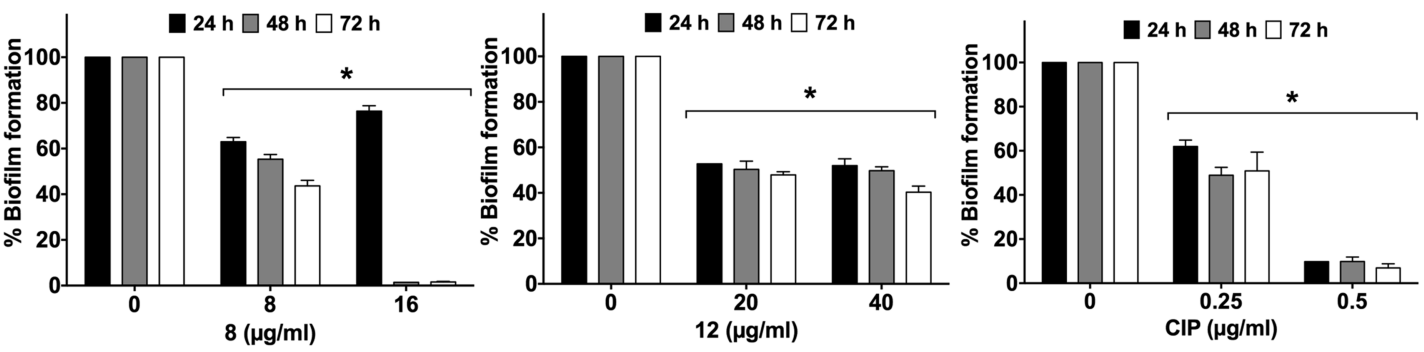

\section{B) S. aureus}
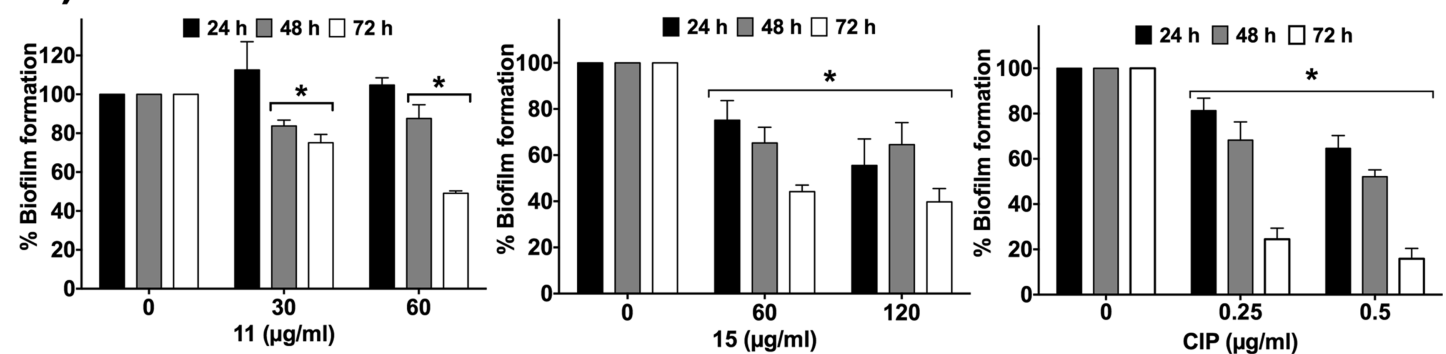

\section{C) E. coli}
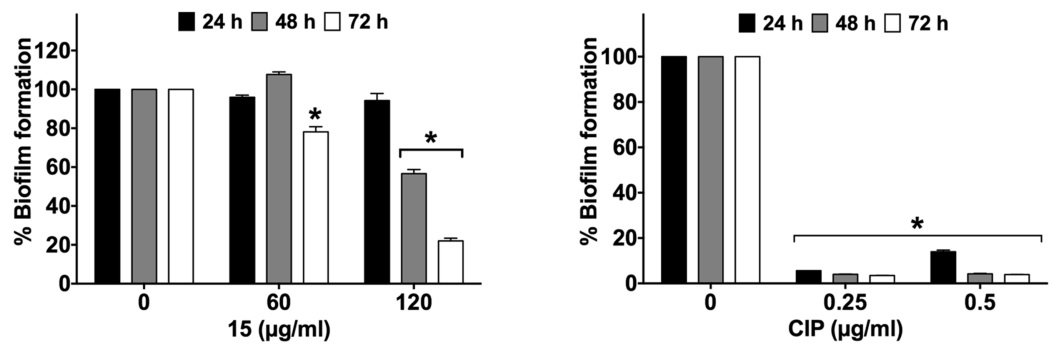

Figure 4. $P$. aeruginosa, Staph. aureus, and E. coli biofilms are inhibited by adding different concentrations of radical scavengers 8, 11, 12, and 15. Bacteria were allowed to grow as biofilms in pegs (in the case of P. aeruginosa) or in wells (in the case of Staph. aureus and E. coli) for $72 \mathrm{~h}$ using 96 well microplates (see Experimental Section). Then, the medium was removed, and fresh medium with different concentrations of radical scavenger compounds were changed every $24 \mathrm{~h}$ over 3 days $(24 \mathrm{~h}, 48 \mathrm{~h}$, and $72 \mathrm{~h}$ ). The percentage of biofilm biomass was calculated by normalizing the data for each of the nontreated biofilms for each day. The results shown are the means \pm SD of four-six replicates from one representative of two independent experiments. A Dunnett's multiple comparison test was performed to detect significant differences. A Student's $t$ test was performed (*, $P<0.05$; vs nontreated biofilms). The viable counts at control experiments without a compound were $2.1 \times 10^{9} \pm 2.8 \times 10^{8}$ colony-forming units $(\mathrm{cfu}) / \mathrm{mL}$ for PAO1, $9.8 \times 10^{9} \pm 3.1 \times 10^{8} \mathrm{cfu} / \mathrm{mL}$ for Staph. aureus, and $3.3 \times 10^{10} \pm 1.8 \times 10^{9} \mathrm{cfu} / \mathrm{mL}$ for E. coli.

istration of selected compounds (one dose $/ 24 \mathrm{~h}$ for three consecutive days), and biofilm biomass was evaluated (Figure
4). CIP, a commonly used and known antibiotic, was used as a positive control. 
A)

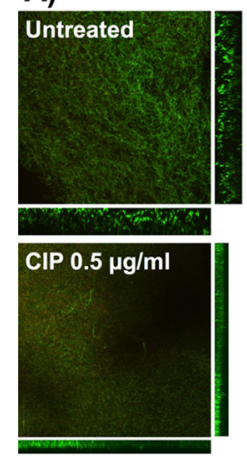

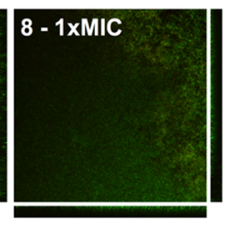

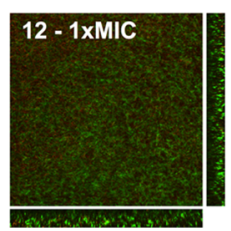

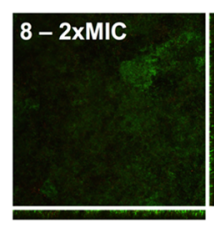

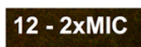

B)

\begin{tabular}{|c|c|c|c|}
\hline & \multicolumn{2}{|c|}{ Live cells (Green) } & \multirow{2}{*}{$\begin{array}{c}\text { Dead Cells } \\
\text { (Red) } \\
\text { Biomass } \\
\left(\mu \mathrm{m}^{3} / \mu \mathrm{m}^{2}\right)\end{array}$} \\
\hline & $\begin{array}{c}\text { Biomass } \\
\left(\mu \mathrm{m}^{3}\right)\end{array}$ & $\begin{array}{c}\text { Thickness } \\
(\mu \mathrm{m})\end{array}$ & \\
\hline $\begin{array}{l}\text { Untreated } \\
8-1 \times M I C\end{array}$ & $\begin{array}{c}29.4 \pm 4 \\
23.8 \pm 2.6^{*}\end{array}$ & $\begin{array}{c}60.1 \pm 4.7 \\
34.9 \pm 8.2^{*}\end{array}$ & $\begin{array}{l}0.03 \pm 0.01 \\
0.48 \pm 0.46^{*}\end{array}$ \\
\hline $8-2 \times M I C$ & $17.9 \pm 2.9^{*}$ & $23.9 \pm 3.7^{*}$ & $3.5 \pm 1.7^{\star}$ \\
\hline 12 - 1xMIC & $19.2 \pm 6.1^{*}$ & $42.1 \pm 4.8^{*}$ & $11.3 \pm 5.1^{*}$ \\
\hline $12-2 x M I C$ & $21.9 \pm 4.1^{*}$ & $27.3 \pm 6.8^{*}$ & $2.6 \pm 1.9^{*}$ \\
\hline CIP $(0.5 \mu \mathrm{g} / \mathrm{ml})$ & $21.6 \pm 3.7^{*}$ & $30.6 \pm 6.6^{*}$ & $1.6 \pm 1.5^{*}$ \\
\hline
\end{tabular}

Figure 5. Effect of compounds 8 and $\mathbf{1 2}$ on a formed flow cell P. aeruginosa biofilm. Flow cell biofilm parameters after treatment with $\mathbf{8}$, 12, and CIP (positive control). P. aeruginosa biofilm was cultured in a flow cell system for $96 \mathrm{~h}$ at room temperature and subjected to a continuous supply of fresh medium at a flow rate of $3 \mathrm{~mL} / \mathrm{h}$. Different concentrations of compounds 8 and 12 and CIP were then used to treat biofilms for $24 \mathrm{~h}$. Afterward, biofilms were dyed with SYTO 9 and propidium iodide, rinsed, and imaged with CLSM. (A) ImageJ-analyzed CLSM micrographs of the differently treated biofilms, showing the sum of the Z-projections and the corresponding orthogonal views of each biofilm (representative of 10 independent areas of two independent experiments). Green cells (dyed with SYTO 9) indicate viable cells, whereas red cells (dyed with propidium iodide) indicate dead cells (damaged membrane). (B) Quantitative flow cell biofilm parameters (biomass and average thickness) of the biofilms, quantified using Comstat2. A Student's $t$ test was performed $(*, P<0.05$, vs nontreated biofilms).

In the case of $P$. aeruginosa (Figure 4A), compound 8 clearly reduced drastically the preestablished biofilm in more than $95 \%$ in $P$. aeruginosa at $48 \mathrm{~h}$ of treatment with an MIC concentration of $16 \mu \mathrm{g} / \mathrm{mL}$. Not so effective, compound 12 reduced above $55 \%$ of the established biofilm after $72 \mathrm{~h}$ of treatment using the highest concentrations. CIP $(0.5 \mu \mathrm{g} / \mathrm{mL})$, used as the positive control, reduced the preestablished biofilm in more than $85 \%$. Compound 8 showed higher activity compared to CIP, demonstrating a good antibacterial activity to eliminate $P$. aeruginosa biofilms.

Not so notorious but also important, compounds 11 and 15, at MIC concentration, efficiently reduced Staph. aureus biofilm at levels around $50 \%$ after $72 \mathrm{~h}$ of treatment (Figure 4B), with similar levels to those reached when treating with CIP (around $60 \%$ reduction).

In the case of E. coli biofilms, compound $\mathbf{1 5}$ also successfully removed static preestablished biofilm at more than $50 \%$ at $72 \mathrm{~h}$ with the highest concentration ( $2 \times$ MIC concentration) (Figure 4C), displaying low antibiofilm activity compared to CIP. CIP-treated biofilm control $(0.25 \mu \mathrm{g} / \mathrm{mL})$ showed a reduction of more than $90 \%$ formed biofilm.

To test some of the compounds under more natural conditions that better resemble the in vivo infections, $P$. aeruginosa continuous-flow biofilms were treated with two of the most effective compounds (8 and 12) and CIP (positive control) (Figure 5A) and observed by confocal laser scanning microscopy (CLSM) demonstrating the capacity of these compounds to decrease biofilm biomass and thickness. Note that under this grown condition, the biofilm is extremely resistant to all known antibiotics (with CIP, the formed biofilm is only reduced around 50\%).

$P$. aeruginosa flow biofilms grew in a characteristic pattern with a lawn of bacterial growth on the surface. These results showed that compounds $\mathbf{8}$ and $\mathbf{1 2}$ at MIC concentration clearly disrupted and inhibited $P$. aeruginosa flow biofilms. Control experiments using CIP showed that a characterized bacterial biofilm decreased, as previously described. ${ }^{32}$ When analyzed using COMSTAT software, $P$. aeruginosa biofilms showed significant structural differences in the presence of both compounds (Figure 5B). Biomass and average thickness decreased in biofilms grown in the presence of $\mathbf{8}$ (more than
50\%) and 12 (more than 30\%), indicating the ability of these new radical scavengers to remove preexisting $P$. aeruginosa growing in flow biofilms with similar results as compared to the benchmarked antibiotic (CIP).

\section{DISCUSSION}

Because of the essential role of RNR in cellular replication, it has been studied for a long time as an antibacterial target, and different RNR inhibitors have been used as antiproliferative therapies in cancer diseases. ${ }^{14,15,17}$ This is the case of HU, a molecule with a hydroxylamine moiety that avoids RNR activity by trapping a radical generated in the activator subunit of the enzyme that is needed to initiate the catalysis.

As there is low similarity between some pathogenic bacteria and the host RNR enzymes, ${ }^{19}$ it is possible to specifically target bacterial enzyme without interfering eukaryotic cells and avoiding host toxicity. In this sense, methyl hydroxylamine, another radical scavenger compound with a hydroxylamine moiety, as $\mathrm{HU}$, was found to show antibacterial activity against both $P$. aeruginosa and Mycobacterium bovis BCG without reducing eukaryotic viability. ${ }^{19,20,23}$ This finding settled the point for the design and development of new radical scavengers with improved antibacterial activity that act against antibiotic multiresistant bacteria.

In previous studies, the direct radical scavenging of the RNR tyrosyl radical in the enzyme was demonstrated to take place when using $\mathrm{HU}$, hydroxylamine, and methylhydroxylamine. ${ }^{20,23}$

Here, we designed and synthesized a small-molecule library of $16 \mathrm{~N}-\mathrm{HAs}$, incorporating six other molecules that were acquired commercially (Figure 1). As the design of the new NHA chemical structures was based on a common $\mathrm{N}$ hydroxylamine moiety as the functional group involved in the radical scavenging, we hypothesized the same mode of action for our new N-HA compounds in RNR inhibition. As expected, we could prove the radical scavenging activity of different active N-HAs by measuring the reduction of the free radical DPPH spectrophotometrically, showing the ability of these compounds to quench free radicals as positive controls, such as AA, HU, and M-HA, do (see Table 2). Moreover, we demonstrated the effect of two of the N-HAs in reducing the intracellular dNTP levels and inducing the protein expression 
of $P$. aeruginosa class I RNR, as $\mathrm{HU}$ does ${ }^{29,33,34}$ (Figure 2), making evident the clear role of these compounds in the inhibition of bacterial RNR enzyme.

Antibacterial activity was assessed for all the library compounds. Although some of the compounds exhibited no antibacterial activity, nine of the new N-HAs were able to inhibit the growth of different bacterial pathogens, including Gram-negative and Gram-positive bacteria (see Table 1).

The library was composed of a wide diversity of structures, including aliphatic and aromatic substituents, to better cover the chemical space and gain selectivity toward the RNR enzyme. As theoretically expected, some of the molecules with cyclic aliphatic groups and aromatic groups showed better activity against bacteria than the ones with linear aliphatic groups, as it has been well described that radical scavenging activities are related to aromatic structures as phenolic compounds. ${ }^{17,35}$ To a great extent, $N$-benzylhydroxylamines with substituents in the aromatic ring $(10,11,12,14,15,17$, and 18) were the ones with higher activity against Grampositive bacterial strains. This statement is also consistent with the fact that lower radical scavenger activity is shown in N-HAs with aliphatic substituents, such as $\mathbf{2 , 3}$, and $\mathbf{6}$, which displayed an $\mathrm{IC}_{50}$ at least 13 times higher than the other evaluated compounds (Table 2). This is probably due to the fact that electron delocalization in the aromatic ring favors the stabilization of the free radical, thus providing higher FRS activity. However, other $N$-benzylhydroxylamine analogues (9, 13, 16, and 19) showed no antibacterial activity, highlighting a lack of structure-activity relationship. We assume that N-HA molecules could quench the free radical in different places along the protein electron chain transfer.

Overall, N-HAs resulted in higher antibacterial activity against Gram-positive species rather than Gram-negative species, excluding $\mathbf{8}$, which showed high activity against both Gram-negative and Gram-positive bacteria. It is clear that some of the new N-HA compounds $(\mathbf{8}, 11,15,17$, and 18) result in higher antimicrobial activity and SI compared to the HU and M-HA. Gram-positive bacteria studied here (B. anthracis, Staph. aureus, Staph. epidermidis, and E. faecalis) encode for a specific class Ib RNR, whereas Gram-negative ( $P$. aeruginosa and E. coli) specifically encode for a class Ia RNR. Particularly, E. coli also encodes for an additional class Ib RNR, although it is not expressed under LB growing conditions. ${ }^{36}$ This difference in RNR subclass is possibly the explanation of such preference for Gram-positive RNR enzymes. We previously described that M-HA showed better specific RNR inhibition for class $\mathrm{Ib} \mathrm{RNR},{ }^{19}$ thus demonstrating better antimicrobial activity in bacteria expressing the class Ib RNR subclass. $^{23}$

How can such a diversity of molecule structures inhibit RNR enzymes? More specifically, where does the radical scavenging of such molecules take place? Class I RNR enzymes are made up of two homodimeric subunits $\left(\alpha_{2} \beta_{2}\right)$ : the large $\alpha_{2}$ homodimeric subunit called $\mathrm{NrdA}$ (class Ia) or $\mathrm{NrdE}$ (class $\mathrm{Ib}$ ) and the small $\beta_{2}$ subunit called $\mathrm{NrdB}$ (class Ia) or NrdF (class $\mathrm{Ib})$. The large subunit $\left(\alpha_{2}\right)$ is the catalytic subunit, which harbors the substrate binding site and reduces the different nucleotides to their corresponding dNTPs, whereas the small $\beta_{2}$ subunit contains an oxygen-linked diferric or dimanganese metal center that generates a free tyrosyl radical. Once the radical is generated, an electron transfer takes place between $\beta_{2}$ and $\alpha_{2}$ subunits from the specific radical site in the small subunit to the substrate binding site in the large subunit by a mechanism involving a long-range electron transfer pathway. $^{11,12}$

Docking experiments with other well-known radical scavenger molecules, $\mathrm{HU}$ and $p$-allyloxyphenol, evidently indicate that the molecule binding site is not well defined and that in most of the cases, radical scavengers are located at the protein surface. ${ }^{35}$ These experiments point out that the large $p$-allyloxyphenol molecule cannot access the tyrosyl radical site directly for structural reasons so that, for these inhibitors, the radical scavenging action needs to be performed during the long-range electron transfer pathway. ${ }^{35}$ Molecules synthesized in this work have similar chemical structures and molecular weights to $p$-allyloxyphenol, so we hypothesize the same radical scavenger activity for the different N-HA molecules described in this work as compared to the $p$ allyloxyphenol. Probably, our N-HA molecules are not able to diffuse to the place where the tyrosyl radical is formed (metal center site at the small class I RNR subunit). Hence, the radical scavenging activity could take place in different places along the protein electron chain transfer. This fact could better explain why different molecular scaffolds can inhibit RNR enzymes with a similar scavenging activity.

Although some of the selected N-HAs displayed certain toxicity to eukaryotic cells, others exhibited good therapeutic index, which is a measure that takes into account both cytotoxicity and antibacterial activity values. $\mathrm{N}$-Hydroxylamine compounds with SI > 5 are interesting and should be well studied to be used as antibiotics, as bacteria were more affected than eukaryotic cells. In addition, when analyzing the lipophilicity levels of the most promising compounds, all of them displayed moderate partition coefficients values, thus indicating good solubility under physiological conditions.

One of the current antimicrobial therapy problems we are currently facing is the use of antibiotics that are not effective to eradicate bacteria growing in biofilms. Under this growing condition, antibiotics cannot penetrate through the extracellular matrix produced by the different bacteria, or if they penetrate, they can be inactivated by some components of the matrix. ${ }^{7}$ This is the reason why bacterial infections growing under biofilm conditions are extremely resistant to the current chemotherapy, thus preventing the infection from being eradicated. For this reason, evaluating antibacterial activity of new molecules in biofilm-growing cells becomes essential if we want to treat current infections.

When testing the ability of our new N-HA molecules to eradicate bacterial biofilms, we found that some of the compounds did reduce biofilm formation at levels similar to those found for other known antibiotics, such as CIP. In the case of $P$. aeruginosa, special attention needs to be done with compound 8 that reduced above $90 \%$ of mature biofilm at $48 \mathrm{~h}$ at the MIC concentration, which is similar to the levels of inhibition with the benchmarked CIP (Figure 4). Not so effective, but also important, were the results obtained with Staph. aureus and E. coli biofilms, especially with a continuous 3 day treatment.

The antibiofilm activities of compound $\mathbf{8}$ were moreover corroborated in a $P$. aeruginosa continuous-flow biofilm, which was stained and observed by CLSM. The results certainly state that compound $\mathbf{8}$ has the same effectivity as CIP to remove well-established and mature $P$. aeruginosa biofilm (with similar biomass and thickness values) (Figure 5).

$P$. aeruginosa is the responsible for some important chronic pulmonary infections, such as those in cystic fibrosis (CF), 
bronchiectasis, or chronic obstructive pulmonary disease (COPD). Our compounds could be effective for those diseases, in which once the infection is established, eradication of $P$. aeruginosa is nearly impossible due to a biofilm form of growth. As the existing therapies always fail to eradicate bacterial biofilms, the results outlined herein show that our compounds could be highly potent and effective drugs to eradicate biofilm infections and open an interesting new era of research in this field. In addition, antibiofilm candidates are ultimately explored to be used not only in clinical settings but also in eliminating contaminating biofilm growth in food and veterinary industry, processes that involve pure water systems.

\section{CONCLUSIONS}

In summary, we designed and synthesized a library of N-HA compounds, acting as radical scavengers, to directly target the bacterial class I RNR enzyme and inhibit bacterial proliferation. Compounds with different structures were designed to better cover the chemical space and gain more selectivity. We have demonstrated the broad antimicrobial effect of several drug candidates against a variety of Gram-positive and Gramnegative pathogenic bacteria, together with low toxicity toward eukaryotic cells. In addition, some of the compounds had the ability to eradicate bacterial biofilms at the same level of known antibiotics. This work settles the starting point to develop new radical scavenger compounds as potential antibacterial agents to fight against drug-resistant pathogenic bacteria.

\section{EXPERIMENTAL SECTION}

All reagents used for chemical synthesis were purchased from commercially available sources and used without further purification. Nuclear magnetic resonance (NMR) solvents were obtained from Sigma-Aldrich. ${ }^{1} \mathrm{H},{ }^{13} \mathrm{C}$, and ${ }^{19} \mathrm{~F}$ NMR spectra were recorded on a Varian MERCURY 400 spectrometer (400 MHz for ${ }^{1} \mathrm{H} \mathrm{NMR}, 101 \mathrm{MHz}$ for ${ }^{13} \mathrm{C}$ $\mathrm{NMR}$, and $376 \mathrm{MHz}$ for ${ }^{19} \mathrm{~F}$ NMR). Chemical shifts $(\delta)$ are expressed in parts per million (ppm) downfield from tetramethylsilane, and deuterated solvent signal was used as reference. Coupling constants $(J)$ are expressed in hertz $(\mathrm{Hz})$. Abbreviations used are $\mathrm{s}=$ singlet, $\mathrm{bs}=$ broad singlet, $\mathrm{d}=$ doublet, $\mathrm{dd}=$ doublets of doublets, $\mathrm{t}=$ triplet, $\mathrm{td}=$ triplets of doublets, $\mathrm{q}=$ quartet, and $\mathrm{m}=$ multiplet. Mass spectra were obtained at the "Centres Cientifics i Tecnologics de la Universitat de Barcelona” (CCiTUB). Compounds tested in the different biological assays were previously diluted to a stock concentration of 0.5 to $1 \mathrm{M}$ in $\mathrm{H}_{2} \mathrm{O}$ to perform the experiments.

General Procedure for the Synthesis and Characterization of N-HAs. N-HAs were synthesized by reductive amination of aldehydes, as described before ${ }^{26}$ with some variations. To a mixture of R-aldehyde ( 1 equiv) in a solution of $5.0 \mathrm{M} \mathrm{LiClO}_{4} / \mathrm{Et}_{2} \mathrm{O}$ (LPDE) $(10 \mathrm{~mL}), \mathrm{O}$-(trimethylsilyl)hydroxylamine (1.5 equiv) was added at room temperature. The mixture was stirred for $10 \mathrm{~min}$, and trimethylsilyl chloride (1.5 equiv) was added. After stirring the mixture for $8 \mathrm{~h}$, borane/triethylamine complex (1.5 equiv) was added, and the reaction mixture was allowed to stir at room temperature overnight. The reaction was quenched with a saturated aqueous $\mathrm{NaHCO}_{3}$ solution to obtain the mono $\mathrm{N}$-alkylhydroxylamine. The mixture was filtrated, and then the product was extracted with DCM. The organic extracts were combined, dried with $\mathrm{MgSO}_{4}$, and concentrated. Finally, the crude product was flash-chromatographed $\left(\mathrm{SiO}_{2}\right)$ using a hexaneEtOAc gradient from 1:0 to 0:1.

All final compounds were confirmed by ${ }^{1} \mathrm{H} \mathrm{NMR},{ }^{13} \mathrm{C}$ NMR, ${ }^{19} \mathrm{~F}$ NMR (see Supporting Information for product characterization), and HR-ESMS. In all cases, the purity of the final product was above $95 \%$ after flash chromatography $\left(\mathrm{SiO}_{2}\right)$.

Compounds 1, 2, 6, 8, 10, 11, 15, 16, 18, and 20 were synthesized as previously described, and their characterization agrees with the literature.

N-Hydroxy-3-methylbutan-1-amine (5). Isovaleraldehyde $(1 \mathrm{~g}, 11.6 \mathrm{mmol})$ was dissolved in a solution of 5.0 M LPDE. Then, $O$-(trimethylsilyl)hydroxylamine $(17.4 \mathrm{mmol})$, trimethylsilyl chloride $(17.4 \mathrm{mmol})$, and borane/TEA complex (17.4 mmol) were added as described in the general procedure. Following purification via flash column chromatography, the product was obtained in a $56.4 \%$ yield. ${ }^{1} \mathrm{H}$ NMR shows a conformer. ${ }^{1} \mathrm{H}$ NMR $\left(400 \mathrm{MHz}, \mathrm{CDCl}_{3}\right) \delta$ ppm 6.48 (bs, 2H, NHOH), 2.93-2.89 (m, 2H, $\left.\mathrm{CH}_{2}\right), 1.65-1.52(\mathrm{~m}$, $1 \mathrm{H}, \mathrm{CH}), 1.41-1.35\left(\mathrm{~m}, 2 \mathrm{H}, \mathrm{CH}_{2}\right), 0.87(\mathrm{~d}, J=6.6 \mathrm{~Hz}, 6 \mathrm{H}$, $\left.\mathrm{CH}_{3}\right)$. Isolated signals of the conformer: $3.38(\mathrm{t}, J=7.4 \mathrm{~Hz}$, $\left.2 \mathrm{H}, \mathrm{CH}_{2}\right), 1.86-1.75(\mathrm{~m}, 1 \mathrm{H}, \mathrm{CH}), 0.90(\mathrm{~d}, J=6.9 \mathrm{~Hz}, 6 \mathrm{H}$, $\left.\mathrm{CH}_{3}\right) .{ }^{13} \mathrm{C}$ NMR $\left(101 \mathrm{MHz},\left(\mathrm{CD}_{3}\right)_{2} \mathrm{CO}\right) \delta \mathrm{ppm} 58.9(\mathrm{t}), 37.7$ (t), 27.5 (d), 23.6 (2q). HRMS (ESI) $\mathrm{m} / z$ calcd for $\mathrm{C}_{5} \mathrm{H}_{14} \mathrm{NO}$ : 104.1075 $[\mathrm{M}+\mathrm{H}]^{+}$; found, 104.1070.

$\mathrm{N}$-(4-Fluoro-2-methylbenzyl)hydroxylamine (12). 4-Fluoro-2-methylbenzaldehyde (1 g, $7.2 \mathrm{mmol})$ was dissolved in a solution of $5.0 \mathrm{M}$ LPDE. Then, $\mathrm{O}$-(trimethylsilyl)hydroxylamine $(10.9 \mathrm{mmol})$, trimethylsilyl chloride (10.9 $\mathrm{mmol})$, and borane/TEA complex $(10.9 \mathrm{mmol})$ were added as described in the general procedure. Following purification via flash column chromatography, the product was obtained in a $55.2 \%$ yield. ${ }^{1} \mathrm{H}$ NMR $\left(400 \mathrm{MHz}, \mathrm{D}_{2} \mathrm{O}\right) \delta \mathrm{ppm} 7.46(\mathrm{dd}, J=$ 8.44, $5.96 \mathrm{~Hz}, 1 \mathrm{H}, \mathrm{ArH}), 7.12(\mathrm{dd}, J=10.05,2.42 \mathrm{~Hz}, 1 \mathrm{H}$, $\mathrm{ArH}), 7.06(\mathrm{td}, J=8.54,2.35 \mathrm{~Hz}, 1 \mathrm{H}, \mathrm{ArH}), 4.51(\mathrm{~s}, 2 \mathrm{H}$, $\left.\mathrm{CH}_{2}\right), 2.43\left(\mathrm{~s}, 3 \mathrm{H}, \mathrm{CH}_{3}\right) \cdot{ }^{13} \mathrm{C}$ NMR $\left(101 \mathrm{MHz}, \mathrm{D}_{2} \mathrm{O}\right) \delta \mathrm{ppm}$ 163.1 (d), 141.7 (s), 133.51 (d), 122.8 (s), 117.4 (d), 113.2 (d), 51.5(t), 18.5 (q). ${ }^{19} \mathrm{~F}$ NMR (376 MHz, $\left.\mathrm{D}_{2} \mathrm{O}\right) \delta \mathrm{ppm}$ $-112.40-(-112.49)(\mathrm{m}, 1 \mathrm{~F}, \mathrm{CF})$. HRMS (ESI) $\mathrm{m} / \mathrm{z}$ calcd for $\mathrm{C}_{8} \mathrm{H}_{11} \mathrm{FNO}: 156.0819[\mathrm{M}+\mathrm{H}]^{+}$; found, 156.0819.

$\mathrm{N}$-(4-Fluoro-2-(trifluoromethyl)benzyl))hydroxylamine (13). 4-Fluoro-2-(trifluoromethyl)benzaldehyde (1 g, 5.2 $\mathrm{mmol}$ ) was dissolved in a solution of 5.0 M LPDE. Then, $O-$ (trimethylsilyl)hydroxylamine $(7.8 \mathrm{mmol})$, trimethylsilyl chloride $(7.8 \mathrm{mmol})$, and borane/TEA complex $(7.8 \mathrm{mmol})$ were added as described in the general procedure. Following purification via flash column chromatography, the product was obtained in a $46.7 \%$ yield. ${ }^{1} \mathrm{H}$ NMR $\left(400 \mathrm{MHz}, \mathrm{CD}_{3} \mathrm{OD}\right)$ $\delta$ ppm 7.89 (dd, $J=8.46,5.26 \mathrm{~Hz}, 1 \mathrm{H}, \mathrm{ArH}), 7.63$ (dd, $J=$ 8.95, $2.72 \mathrm{~Hz}, 1 \mathrm{H}, \mathrm{ArH}), 7.55$ (td, $J=8.46,2.72 \mathrm{~Hz}, 1 \mathrm{H}, \mathrm{ArH}$ ), 4.93 (bs, 2H, NHOH), $4.61\left(\mathrm{~s}, 2 \mathrm{H}, \mathrm{CH}_{2}\right) \cdot{ }^{13} \mathrm{C} \mathrm{NMR}(101$ $\left.\mathrm{MHz}, \mathrm{CD}_{3} \mathrm{OD}\right) \delta$ ppm 164.3 (d), 137.2 (d), 133.2 (s), 124.7 (s), $124.5(\mathrm{q}), 120.9$ (d), $115.5(\mathrm{~d}), 52.1(\mathrm{t}) .{ }^{19} \mathrm{~F}$ NMR (376 $\left.\mathrm{MHz}, \mathrm{CD}_{3} \mathrm{OD}\right) \delta \mathrm{ppm}-60.22\left(\mathrm{~s}, 3 \mathrm{~F}, \mathrm{CF}_{3}\right),-110.52-$ $(-110.57)(\mathrm{m}, 1 \mathrm{~F}, \mathrm{CF})$. HRMS (ESI) $\mathrm{m} / z$ calcd for $\mathrm{C}_{8} \mathrm{H}_{8} \mathrm{~F}_{4} \mathrm{NO}: 210.0537[\mathrm{M}+\mathrm{H}]^{+}$; found, 210.0546 .

$\mathrm{N}$-(3,5-Difluorobenzyl)hydroxylamine (14). 3,5-Difluorobenzaldehyde ( $1 \mathrm{~g}, 7 \mathrm{mmol})$ was dissolved in a solution of 5.0 M LPDE. Then, O-(trimethylsilyl)hydroxylamine (10.6 $\mathrm{mmol})$, trimethylsilyl chloride $(10.6 \mathrm{mmol})$, and borane/TEA complex $(10.6 \mathrm{mmol})$ were added as described in the general procedure. Following purification via flash column chromatography, the product was obtained in a $49.8 \%$ yield. ${ }^{1} \mathrm{H}$ NMR 
(400 MHz, $\left.\mathrm{D}_{2} \mathrm{O}\right) \delta$ ppm 7.25-7.03 (m, 3H, ArH), $4.47(\mathrm{~s}$, $\left.2 \mathrm{H}, \mathrm{CH}_{2}\right) .{ }^{13} \mathrm{C}$ NMR (101 MHz, $\left.\mathrm{D}_{2} \mathrm{O}\right) \delta \mathrm{ppm} 162.8$ (d), 162.7 (d), $132.0(\mathrm{~s}), 113.7(2 \mathrm{~d}), 105.2(\mathrm{~d}), 53.74(\mathrm{t}) \cdot{ }^{19} \mathrm{~F}$ NMR (376 MHz, $\left.\mathrm{D}_{2} \mathrm{O}\right) \delta \mathrm{ppm}-109.33-(-109.46)(\mathrm{m}, 2 \mathrm{~F}$, CF). HRMS (ESI) $m / z$ calcd for $\mathrm{C}_{7} \mathrm{H}_{8} \mathrm{~F}_{2} \mathrm{NO}: 160.0568[\mathrm{M}+$ $\mathrm{H}]^{+}$; found, 160.0568 .

$\mathrm{N}$-(4-Methoxy-2-methylbenzyl)hydroxylamine (17). 4-Methoxy-2-methylbenzaldehyde $(1 \mathrm{~g}, 6.7 \mathrm{mmol})$ was dissolved in a solution of $5.0 \mathrm{M}$ LPDE. Then, $O$-(trimethylsilyl)hydroxylamine $(10 \mathrm{mmol})$, trimethylsilyl chloride (10 mmol), and borane/TEA complex $(10 \mathrm{mmol})$ were added as described in the general procedure. Following purification via flash column chromatography, the product was obtained in a $32.8 \%$ yield. ${ }^{1} \mathrm{H}$ NMR $\left(400 \mathrm{MHz}, \mathrm{CDCl}_{3}\right) \delta \mathrm{ppm} 7.18$ (d, $J=$ $8.2 \mathrm{~Hz}, 1 \mathrm{H}, \mathrm{ArH}), 6.73$ (d, $J=2.7 \mathrm{~Hz}, 1 \mathrm{H}, \operatorname{ArH}), 6.70$ (dd, $J=$ 8.2, $2.7 \mathrm{~Hz}, 1 \mathrm{H}, \mathrm{ArH}), 4.00\left(\mathrm{~s}, 2 \mathrm{H}, \mathrm{CH}_{2}\right), 3.78\left(\mathrm{~s}, 3 \mathrm{H}, \mathrm{CH}_{3}\right)$, $2.35\left(\mathrm{~s}, 3 \mathrm{H}, \mathrm{CH}_{3}\right) .{ }^{13} \mathrm{C} \mathrm{NMR}\left(101 \mathrm{MHz}, \mathrm{CDCl}_{3}\right) \delta \mathrm{ppm} 158.9$ (s), 138.4 (s), 131.3 (d), 126.6 (s), 115.8 (d), 110.8 (d), 54.9 (q), 54.9 (t), 19.1 (q). HRMS (ESI) $m / z$ calcd for $\mathrm{C}_{9} \mathrm{H}_{14} \mathrm{NO}_{2}$ : $168.1025[\mathrm{M}+\mathrm{H}]^{+}$; found, 168.1027 .

N-(2,6-Dimethoxybenzyl)hydroxylamine (19). 2,6-Dimethoxybenzaldehyde $(1 \mathrm{~g}, 6 \mathrm{mmol})$ was dissolved in a solution of 5.0 M LPDE. Then, O-(trimethylsilyl)hydroxylamine (9 mmol), trimethylsilyl chloride ( $9 \mathrm{mmol})$, and borane/TEA complex $(9 \mathrm{mmol})$ were added as described in the general procedure. Following purification via flash column chromatography, the product was obtained in a $29.8 \%$ yield. ${ }^{1} \mathrm{H}$ NMR $\left(400 \mathrm{MHz}, \mathrm{CDCl}_{3}\right) \delta \mathrm{ppm} 7.19(\mathrm{t}, J=8.4 \mathrm{~Hz}, 1 \mathrm{H}, \mathrm{ArH}), 6.54$ (d, $J=8.4 \mathrm{~Hz}, 2 \mathrm{H}, \mathrm{ArH}), 3.93\left(\mathrm{~s}, 2 \mathrm{H}, \mathrm{CH}_{2}\right), 3.81(\mathrm{~s}, 6 \mathrm{H}$, $\left.\mathrm{CH}_{3}\right) \cdot{ }^{13} \mathrm{C}$ NMR $\left(101 \mathrm{MHz}, \mathrm{CDCl}_{3}\right) \delta \mathrm{ppm} 159.4(2 \mathrm{~s}), 128.6$ (d), 114.4 (s), 103.9 (2d), 55.8 (2q), 47.9 (t). HRMS (ESI) $m / z$ calcd for $\mathrm{C}_{9} \mathrm{H}_{13} \mathrm{NO}_{3}: 184.0968[\mathrm{M}+\mathrm{H}]^{+}$; found, 184.0964

Log $P$ Calculations. The compounds were equilibrated in a two-phase octanol-water system in small vials, and highperformance liquid chromatography (HPLC) was used to determine the concentration of the compounds in each phase. Compound concentrations ( $c i$ ) were calculated using the expression $c i=k I i$, where $I i$ is the integral under the peak of the HPLC chromatogram and the proportionality constant $k$ is called the response factor. The ratio of the integrals for the octanol and water phase gave the partition coefficient $(P)$ :

$$
\begin{aligned}
P & =c i(\text { octanol }) / c i(\text { water })=k I i(\text { octanol }) / k I i(\text { water }) \\
& =I i(\text { octanol }) / I i(\text { water })
\end{aligned}
$$

Bacterial Strains and Growth Conditions. Wild-type $P$. aeruginosa ATCC 15692 (CECT 4122), Staph. aureus ATCC 12600 (CECT 86), Staph. epidermidis ATCC 1798 (CECT 231), and E. faecalis ATCC 19433 (CECT 481) were obtained from the Spanish Type Culture Collection (CECT). E. coli O157:H7 $\Delta s t x$ was obtained from laboratory collection, and $B$. anthracis Sterne $7700 \mathrm{pXO}^{-} / \mathrm{pXO}^{-}$was obtained from the Swedish Defence Research Agency. These strains were stored at $-80{ }^{\circ} \mathrm{C}$ as glycerol stocks. To obtain inocula for examination, the strains were cultured overnight on trypticase soy agar (TSA) (Scharlau, Spain) or Luria agar (Scharlau, Spain) at $37^{\circ} \mathrm{C}$. Tryptic soy broth (TSB) (Sharlau, Spain) or Luria Broth (LB) was used to culture bacteria at $37{ }^{\circ} \mathrm{C}$.

The murine macrophage J774.A1 cell line (DSMZ ACC 170) was maintained in Dulbecco's Modified Eagle's medium (DMEM) with L-glutamine (Gibco BRL, Grand Island, NY) supplemented with $10 \%$ heat-inactivated fetal bovine serum
(FBS, Lonza Ltd., Switzerland), containing $100 \mathrm{U} / \mathrm{mL}$ penicillin G (Lab ERN, Barcelona, Spain) and $100 \mu \mathrm{g} / \mathrm{mL}$ streptomycin (Reig Jofre Laboratory, Barcelona, Spain) (complete medium), at $37{ }^{\circ} \mathrm{C}$ in a humidified atmosphere with $5 \% \mathrm{CO}_{2}$.

Antibacterial Susceptibility Testing. To determine survival of the different strains in the presence of different potential inhibitors, each bacterial strain was grown in TSB medium to initial exponential log phase $\left(\mathrm{OD}_{550} \approx 0.1\right)$ and plated in a microtiter plate with different concentrations of the antimicrobial agents, following the Clinical Laboratory Standards Institute (CLSI) guidelines. ${ }^{37}$ Growth curves were monitored for $8 \mathrm{~h}$, taking the $\mathrm{OD}_{550} \mathrm{~nm}$ every $15 \mathrm{~min}$ in a microplate reader (Infinite M200 Microplate Reader, Tecan). Bacteria diluted in media with no compound were used as a positive control of bacterial growth.

The minimal inhibitory concentration 50\% $\left(\mathrm{MIC}_{50}\right)$ was defined as the compound concentration that reduces bacterial growth, determined as the $\mathrm{OD}_{550}$, by $50 \%$.

Determination of Mammalian Cytotoxicity. Murine macrophage cells $\left(6 \times 10^{4}\right.$ per well $)$ were seeded onto 48 well tissue culture plates in complete medium (Gibco) without antibiotics, in the presence of different doses of compounds or left untreated. After $24 \mathrm{~h}$ of exposure to the different compounds, culture supernatants were removed, and cell viability were measured by the addition of $10 \%(\mathrm{w} / \mathrm{v})$ of 3 (4,5-dimethylthiazol-2-yl)-2,5-diphenyltetrazolium bromide (MTT) in complete medium was added and incubated for 3 $\mathrm{h}$ at $37{ }^{\circ} \mathrm{C}$. Then, water-insoluble dark blue formazan was dissolved by adding acidic isopropanol. Absorbance was measured at $550 \mathrm{~nm}$ using a microplate reader (Infinite M200 Microplate Reader, Tecan). Results were expressed as the percent absorbance of treated versus untreated control cultures.

The $50 \%$ cytotoxicity inhibitory concentration $\left(\mathrm{CC}_{50}\right)$ of each drug was determined from dose-response curves. On the basis of the $\mathrm{CC}_{50}(24 \mathrm{~h})$ and $\mathrm{MIC}_{50}(8 \mathrm{~h})$ values, the selectivity index $\left(\mathrm{SI}=\mathrm{CC}_{50} / \mathrm{MIC}_{50}\right)$ was calculated.

Fluorescent Microscopy Viability Test Analysis. Overnight cultures of B. anthracis, Staph. aureus, $P$. aeruginosa, and E. coli were diluted in fresh TSB or LB medium, grown to the beginning of exponential phase $\left(\mathrm{OD}_{550} \approx 0.3\right)$, and different compound concentrations were added. After $3 \mathrm{~h}$ of incubation at $37{ }^{\circ} \mathrm{C}$ under shaking conditions, cells were harvested and stained using the LIVE/DEAD BacLight Bacterial Viability Kit (Molecular Probes) for $30 \mathrm{~min}$ at room temperature under dark conditions, followed by one sterile phosphate-buffered saline (PBS) wash to remove nonspecific stain. Fluorescent bacteria were visualized by a Nikon inverted fluorescent microscope ECLIPSE Ti-S/L100 (Nikon) coupled with a DSQi2 Nikon camera.

Static Biofilm Formation Assay. P. aeruginosa PAO1 static biofilms were grown on microplates following the protocol previously described. ${ }^{32,38}$ An overnight grown culture of $P$. aeruginosa in TSB was diluted to an $\mathrm{OD}_{550}$ of 0.1 in sterile TSB medium supplemented with $0.2 \%$ glucose and added to a 96 well microtiter plate with pegs (Nunc-TSP, Thermo Scientific) $(200 \mu \mathrm{L}$ per well). After $24-48 \mathrm{~h}$ incubation at $37{ }^{\circ} \mathrm{C}$ in a humid chamber, the culture supernatant was discarded, and the pegs were washed three times with sterile PBS to remove nonadherent cells. After rinsing, the biofilms were treated with different radical scavenger's concentrations using twofold serial dilutions in TSB medium supplemented 
with $0.2 \%$ glucose. After $24 \mathrm{~h}$ of treatment, peg lids were transferred to a new plate and rinsed three times with PBS. Adherent bacteria were first fixed with $98 \%$ methanol for 15 min, allowed to dry for $5 \mathrm{~min}$, and then stained with crystal violet (1\%) for $10 \mathrm{~min}$. An excess of crystal violet was washed gently with water, and pegs were dried in air for $5 \mathrm{~min}$. The dye bound to the cells was dissolved with acetic acid 33\%, and absorbance was read with a microplate reader (Infinite M200 Pro Multimode Microplate Reader, Tecan) at a wavelength of $570 \mathrm{~nm}$.

The static biofilm formation assay for Staph. aureus and E. coli was assessed following the previous protocol but using flatbottom 96 well polystyrene plates with lid (tissue culturetreated polystyrene, Costar 3596, Corning Inc., NY), in the case of Staph. aureus, and 96 well PVC plates, in the case of E. coli. $^{36}$

Flow Cell Biofilm Assay. P. aeruginosa biofilm formed under a continuous flow was cultured in a flow cell system, as previously described ${ }^{32,39}$ with some modifications. Channel flow cells (made of Perspex poly(methyl methacrylate)), with a channel size of $40 \times 4 \times 1 \mathrm{~mm}$ (DTU Systems Biology, Technical University of Denmark)), were used and covered with a no. $124 \times 50 \mathrm{~mm}$ glass coverslip (Deltalab, ref D102450), which served as the biofilm substratum. Each flow cell channel was inoculated with $350 \mu \mathrm{L}$ of a $P$. aeruginosa culture, diluted to an $\mathrm{OD}_{550}=0.1$, and left without medium flow for $1 \mathrm{~h}$. The biofilm was then allowed to grow in LB medium supplemented with $0.04 \%$ glucose under nutrient flow conditions $(3 \mathrm{~mL} / \mathrm{h})$ for $96 \mathrm{~h}$ at room temperature. The flow was then stopped, and different concentrations of compounds and CIP diluted in the medium were injected afterward to the formed biofilms. Medium without any added compound was injected in a channel as a control for biofilms without treatment. After $24 \mathrm{~h}$, treated biofilms were dyed with $6 \mu \mathrm{M}$ SYTO 9 and $30 \mu \mathrm{M}$ propidium iodide (LIVE/DEAD BacLight Bacterial Viability Kit (Molecular Probes)) for 30 min under dark conditions and afterward washed with PBS. Biofilms were imaged with CLSM (Leica TCS-SP5, Leica Microsystems, Heidelberg, Germany) using excitation and emission wavelengths of 488 and $514 \mathrm{~nm}$, respectively. Sections $(250 \times 250$ $\mu \mathrm{m})$ were scanned at a $40 \times$ magnification, and $Z$-stacks were obtained with a $z$-step size of $0.388 \mu \mathrm{m}$. The acquired images were analyzed using ImageJ software (National Institute of Health, USA) and Comstat 2 software, ${ }^{40}$ which were used to quantify biofilm biomass and thickness.

Radical Scavenging Activity Determination. The capacity of the N-HA compounds to scavenge free radicals was evaluated by determining the in vitro scavenging of the stable free radical DPPH. (Sigma-Aldrich), which has an absorption peak at $517 \mathrm{~nm}$ in its radical form. Twofold dilutions of the different compounds were prepared in methanol in a 96 well microplate with final concentrations ranging from 256 to $0.5 \mu \mathrm{M}$, and $\mathrm{DPPH}$ - dissolved in methanol was added to initiate the reaction with a final concentration of $70 \mu \mathrm{M}$. The microplate was incubated at $30^{\circ} \mathrm{C}$ under dark conditions, and the absorbance was read at $517 \mathrm{~nm}$ after 8 and $12 \mathrm{~h}$ of incubation using a microplate reader (Infinite M200 Microplate Reader, Tecan). AA and HU were used as reference radical scavengers. The percentage of radical inhibition was calculated using the absorbance value of $70 \mu \mathrm{M} \mathrm{DPPH}$. without any compound as a reference, and the $\mathrm{IC}_{50}$ value for each compound was calculated from the linear interval of the curve.
Analysis of NrdA Expression Using Western Immuno-

blot. P. aeruginosa PAO1 NrdA expression was determined in protein extracts from cultures in the presence or absence of $\mathrm{N}$ HA compounds or HU. To do so, Western blot was performed, as previously described. ${ }^{20}$ SDS-PAGE with normalized protein extracts was run, transfer was carried out in a PVDF membrane, and blotting was done using anti-NrdA rabbit polyclonal antibody (Agrisera, Sweden) at a $1 / 750$ dilution and Goat Anti-Rabbit IgG HRP Conjugate (Bio-Rad) as a secondary antibody at a 1/500 dilution. Amersham ECL Prime Western Blotting Detection Reagent (GE Healthcare) was used for chemiluminescence detection and visualized using the LAS4000 mini system (GE Healthcare).

DPA Assay for dNTP Quantification. dNTP levels in P. aeruginosa PAO1 cultures were determined following the DPA assay for purine dNTP estimation, as previously described. ${ }^{28,29}$ Bacterial pellets from PAO1 cultured in the presence or absence of $\mathrm{N}-\mathrm{HA}$ compounds or $\mathrm{HU}$ were suspended in a lysis buffer (50 mM Tris-HCl, pH 7.4, 100 mM NaCl, 5 mM DTT, $5 \%$ glycerol), sonicated in an ultrasonic processor (Branson Sonifier SFX550) until clear, and centrifuged at 20,000 $\mathrm{g}$ for 30 min. Pellet was discarded, and the protein concentration of bacterial extracts was quantified using Bradford assay (Bio$\mathrm{Rad}$ ). Protein concentration was then adjusted for all the samples, and $0.1 \mathrm{~mL}$ of each extract was mixed with $0.4 \mathrm{~mL}$ of $0.5 \mathrm{M}$ chloroacetamide in $0.25 \mathrm{M}$ potassium phosphate buffer ( $\mathrm{pH} 7.3)$. The mixture was incubated for $10 \mathrm{~min}$ at $90{ }^{\circ} \mathrm{C}$ and cooled to room temperature, and $2 \mathrm{~mL}$ of DPA reagent $(2 \mathrm{~g}$ of DPA dissolved in $100 \mathrm{~mL}$ of acetic acid and $2.75 \mathrm{~mL}$ of sulfuric acid) was added and incubated at $38{ }^{\circ} \mathrm{C}$ for $4 \mathrm{~h}$. Absorbance values at a wavelength of $595 \mathrm{~nm}$ were used to determine relative dNTP levels.

Statistical Analysis. All data were statistically analyzed using GraphPad Prism version 6.00 for Mac OS X (GraphPad Software, USA).

\section{ASSOCIATED CONTENT}

\section{S Supporting Information}

The Supporting Information is available free of charge on the ACS Publications website at DOI: 10.1021/acsomega.8b01384.

${ }^{1} \mathrm{H}$ NMR, ${ }^{13} \mathrm{C}$ NMR, and ${ }^{19} \mathrm{~F}$ NMR spectra of all synthesized N-HA compounds (PDF)

\section{AUTHOR INFORMATION}

\section{Corresponding Authors}

*E-mail: albericio@ub.edu (F.A.).

*E-mail: etorrents@ibecbarcelona.eu (E.T.)

ORCID

Fernando Albericio: 0000-0002-8946-0462

Eduard Torrents: 0000-0002-3010-1609

\section{Author Contributions}

\#These authors contributed equally to this work.

\section{Author Contributions}

The manuscript was written through contributions of all authors. All authors have given approval to the final version of the manuscript. L.M.-C. and A.B. contributed equally to this work. L.M.-C. designed and synthesized the library of $\mathrm{N}$ hydroxylamines analogues and wrote the manuscript. A.B. and E.J. performed biological assays and wrote the manuscript. J.A. performed flow biofilm inhibition assays. A.L.-R. synthesized 
$N$-hydroxylamines compounds. F.A. directed the research and revised the experimental data. E.T. directed the research, revised the experimental data, and wrote the manuscript.

\section{Funding}

This study was partially supported by grants from the Ministerio de Economia y Competitividad (BIO2015-63557-R, SAF2015-63867-R, and CTQ2015-67870-P), AGAUR-Generalitat de Catalunya (2017SGR-229, 2014SGR-1260, 2014SGR137, and 2017SGR-1079), the European Regional Development Fund (FEDER), Catalan and Spanish cystic fibrosis federation, the EIT Health, and Obra Social "La Caixa" to E.T., E.J., and F.A.

\section{Notes}

The authors declare no competing financial interest.

\section{ACKNOWLEDGMENTS}

A.B. is thankful to the Ministerio de Educación, Cultura y Deporte for its financial support through the FPU programme (FPU13/06083).

\section{ABBREVIATIONS}

RNR, ribonucleotide reductase; MIC, minimum inhibitory concentration; CFU, colony-forming units; FRS, free-radical scavengers

\section{REFERENCES}

(1) Boucher, H. W.; Talbot, G. H.; Bradley, J. S.; Edwards, J. E.; Gilbert, D.; Rice, L. B.; Scheld, M.; Spellberg, B.; Bartlett, J. Bad bugs, No Drugs: No ESKAPE! An Update from the Infectious Diseases Society of America. Clin. Infect. Dis. 2009, 48, 1-12.

(2) Fair, R. J.; Tor, Y. Antibiotics and Bacterial Resistance in the 21st Century. Perspect. Med. Chem. 2014, 6, 25-64.

(3) Lebeaux, D.; Ghigo, J.-M.; Beloin, C. Biofilm-Related Infections: Bridging the Gap between Clinical Management and Fundamental Aspects of Recalcitrance toward Antibiotics. Microbiol. Mol. Biol. Rev. 2014, 78, 510-543.

(4) Bryers, J. D. Medical Biofilms. Biotechnol. Bioeng. 2008, 100, 118.

(5) Costerton, J. W.; Stewart, P. S.; Greenberg, E. P. Bacterial Biofilms: A Common Cause of Persistent Infections. Science 1999, 284, 1318-1322.

(6) Hall-Stoodley, L.; Stoodley, P. Evolving Concepts in Biofilm Infections. Cell. Microbiol. 2009, 11, 1034-1043.

(7) Høiby, N.; Bjarnsholt, T.; Givskov, M.; Molin, S.; Ciofu, O. Antibiotic Resistance of Bacterial Biofilms. Int. J. Antimicrob. Agents 2010, 35, 322-332.

(8) Sadekuzzaman, M.; Yang, S.; Mizan, M. F. R.; Ha, S. D. Current and Recent Advanced Strategies for Combating Biofilms. Compr. Rev. Food Sci. Food Saf. 2015, 14, 491-509.

(9) Torrents, E. Ribonucleotide Reductases: Essential Enzymes for Bacterial Life. Front. Cell. Infect. Microbiol. 2014, 4, 52.

(10) Lundin, D.; Berggren, G.; Logan, D. T.; Sjöberg, B.-M. The Origin and Evolution of Ribonucleotide Reduction. Life 2015, 5, 604-636.

(11) Hofer, A.; Crona, M.; Logan, D. T.; Sjöberg, B.-M. DNA Building Blocks: Keeping Control of Manufacture. Crit. Rev. Biochem. Mol. Biol. 2012, 47, 50-63.

(12) Cotruvo, J. A., Jr.; Stubbe, J. Class I Ribonucleotide Reductases: Metallocofactor Assembly and Repair in Vitro and in Vivo. Annu. Rev. Biochem. 2011, 80, 733-767.

(13) Lundin, D.; Gribaldo, S.; Torrents, E.; Sjöberg, B.-M.; Poole, A. M. Ribonucleotide Reduction - Horizontal Transfer of a Required Function Spans All Three Domains. BMC Evol. Biol. 2010, 10, 383.

(14) Cerqueira, N. M. F. S. A.; Fernandes, P. A.; Ramos, M. J. Ribonucleotide Reductase: A Critical Enzyme for Cancer Chemo- therapy and Antiviral Agents. Recent Pat. Anti-Cancer Drug Discovery 2007, 2, 11-29.

(15) Aye, Y.; Li, M.; Long, M. J. C.; Weiss, R. S. Ribonucleotide Reductase and Cancer: Biological Mechanisms and Targeted Therapies. Oncogene 2015, 34, 2011-2021.

(16) Moorthy, N. S. H. N.; Cerqueira, N. M. F. S. A.; Ramos, M. J.; Fernandes, P. A. Development of Ribonucleotide Reductase Inhibitors: A Review on Structure Activity Relationships. Mini-Rev. Med. Chem. 2013, 13, 1862-1872.

(17) Saban, N.; Bujak, M. Hydroxyurea and Hydroxamic Acid Derivatives as Antitumor Drugs. Cancer Chemother. Pharmacol. 2009, 64, 213-221.

(18) Basu, A.; Sinha, B. N. Radical Scavengers as Ribonucleotide Reductase Inhibitors. Curr. Top. Med. Chem. 2012, 12, 2827-2842.

(19) Torrents, E.; Sahlin, M.; Biglino, D.; Gräslund, A.; Sjöberg, B.M. Efficient Growth Inhibition of Bacillus anthracis by Knocking Out the Ribonucleotide Reductase Tyrosyl Radical. Proc. Natl. Acad. Sci. U. S. A. 2005, 102, 17946-17951.

(20) Torrents, E.; Sjöberg, B.-M. Antibacterial Activity of Radical Scavengers against Class Ib Ribonucleotide Reductase from Bacillus anthracis. Biol. Chem. 2010, 391, 229-234.

(21) Wang, E. S. Treating Acute Myeloid Leukemia in Older Adults. Hematology 2014, 2014, 14-20.

(22) Ferrara, F. Conventional Chemotherapy or Hypomethylating Agents for Older Patients with Acute Myeloid Leukaemia? Hematol. Oncol. 2014, 32, 1-9.

(23) Julián, E.; Baelo, A.; Gavaldà, J.; Torrents, E. MethylHydroxylamine as an Efficacious Antibacterial Agent that Targets the Ribonucleotide Reductase Enzyme. PLoS One 2015, 10, e0122049.

(24) Amorati, R.; Lucarini, M.; Mugnaini, V.; Pedulli, G. F.; Minisci, F.; Recupero, F.; Fontana, F.; Astolfi, P.; Greci, L. Hydroxylamines as Oxidation Catalysts: Thermochemical and Kinetic Studies. J. Org. Chem. 2003, 68, 1747-1754.

(25) Dao, R.; Wang, X.; Chen, K.; Zhao, C.; Yao, J.; Li, H. Landscape of the Structure-O-H Bond Dissociation Energy Relationship of Oximes and Hydroxylamines. Phys. Chem. Chem. Phys. 2017, 19, 22309-22320.

(26) Heydari, A.; Tavakol, H.; Aslanzadeh, S.; Azarnia, J.; Ahmadi, N. A General One-Pot, Three-Component Mono N-Alkylation of Amines and Amine Derivatives in Lithium Perchlorate/Diethyl Ether Solution. Synthesis 2005, 2005, 627-633.

(27) Saiko, P.; Steinmann, M.-T.; Schuster, H.; Graser, G.; Bressler, S.; Giessrigl, B.; Lackner, A.; Grusch, M.; Krupitza, G.; Bago-Horvath, Z.; Jaeger, W.; Fritzer-Szekeres, M.; Szekeres, T. Epigallocatechin Gallate, Ellagic Acid, and Rosmarinic Acid Perturb dNTP Pools and Inhibit De Novo DNA Synthesis and Proliferation of Human HL-60 Promyelocytic Leukemia Cells: Synergism with Arabinofuranosylcytosine. Phytomedicine 2015, 22, 213-222.

(28) Blakley, R. L. Cobamides and Ribonucleotide Reduction. II. Estimation of the Enzymic Formation of Purine and Pyrimidine Deoxyribonucleotides by the Use of the Diphenylamine Reagent. J. Biol. Chem. 1966, 241, 176-179.

(29) Crespo, A.; Pedraz, L.; Torrents, E. Function of the Pseudomonas aeruginosa NrdR Transcription Factor: Global Transcriptomic Analysis and Its Role on Ribonucleotide Reductase Gene Expression. PLoS One 2015, 10, e0123571.

(30) Filpula, D.; Fuchs, J. A. Regulation of the Synthesis of Ribonucleoside Diphosphate Reductase in Escherichia coli: Specific Activity of the Enzyme in Relationship to Perturbations of DNA Replication. J. Bacteriol. 1978, 135, 429-435.

(31) Lebeaux, D.; Chauhan, A.; Rendueles, O.; Beloin, C. From in Vitro to in Vivo Models of Bacterial Biofilm-Related Infections. Pathogens 2013, 2, 288-356.

(32) Baelo, A.; Levato, R.; Julián, E.; Crespo, A.; Astola, J.; Gavaldà, J.; Engel, E.; Mateos-Timoneda, M. A.; Torrents, E. Disassembling Bacterial Extracellular Matrix with DNase-Coated Nanoparticles To Enhance Antibiotic Delivery in Biofilm Infections. J. Controlled Release 2015, 209, 150-158. 
(33) Sjöberg, B.-M.; Torrents, E. Shift in Ribonucleotide Reductase Gene Expression in Pseudomonas aeruginosa during Infection. Infect. Immun. 2011, 79, 2663-2669.

(34) Torrents, E.; Poplawski, A.; Sjöberg, B.-M. Two Proteins Mediate Class II Ribonucleotide Reductase Activity in Pseudomonas aeruginosa: Expression and Transcriptional Analysis of the Aerobic Enzymes. J. Biol. Chem. 2005, 280, 16571-16578.

(35) Luo, J.; Graslund, A. Ribonucleotide Reductase Inhibition by $p$ Alkoxyphenols Studied by Molecular Docking and Molecular Dynamics Simulations. Arch. Biochem. Biophys. 2011, 516, 29-34.

(36) del Mar Cendra, M.; Juárez, A.; Torrents, E. Biofilm Modifies Expression of Ribonucleotide Reductase Genes in Escherichia coli. PLoS One 2012, 7, e46350.

(37) Clinical and Laboratory Standards Institute. Methods for Dilution and Antimicrobial Susceptibility Test for Bacteria that Grow Aerobically: Approved Standard, 7th ed.; CLSI Document M7-A7; Clinical and Laboratory Standards Institute: Wayne, PA, 2006.

(38) Harrison, J. J.; Stremick, C. A.; Turner, R. J.; Allan, N. D.; Olson, M. E.; Ceri, H. Microtiter Susceptibility Testing of Microbes Growing on Peg Lids: A Miniaturized Biofilm Model for HighThroughput Screening. Nat. Protoc. 2010, 5, 1236-1254.

(39) Christensen, B. B.; Sternberg, C.; Andersen, J. B.; Palmer, R. J., Jr.; Nielsen, A. T.; Givskov, M.; Molin, S. [2] Molecular Tools for Study of Biofilm Physiology. Methods Enzymol. 1999, 310, 20-42.

(40) Heydorn, A.; Nielsen, A. T.; Hentzer, M.; Sternberg, C.; Givskov, M.; Ersb $\varnothing l l$, B. K.; Molin, S. Quantification of Biofilm Structures by the Novel Computer Program COMSTAT. Microbiology 2000, 146, 2395-2407. 